\title{
Genome-wide identification and analysis of class III peroxidases in Betula pendula
}

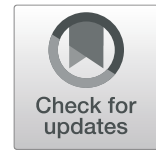

\author{
Kewei Cai ${ }^{\dagger}$, Huixin Liu, Song Chen ${ }^{\dagger}$, Yi Liu, Xiyang Zhao and Su Chen ${ }^{*}$ id
}

\begin{abstract}
Background: Class III peroxidases (POD) proteins are widely present in the plant kingdom that are involved in a broad range of physiological processes including stress responses and lignin polymerization throughout the plant life cycle. At present, POD genes have been studied in Arabidopsis, rice, poplar, maize and Chinese pear, but there are no reports on the identification and function of $P O D$ gene family in Betula pendula.

Results: We identified 90 nonredundant POD genes in Betula pendula. (designated BPPODs). According to phylogenetic relationships, these POD genes were classified into 12 groups. The BPPODs are distributed in different numbers on the 14 chromosomes, and some BPPODs were located sequentially in tandem on chromosomes. In addition, we analyzed the conserved domains of BPPOD proteins and found that they contain highly conserved motifs. We also investigated their expression patterns in different tissues, the results showed that some BpPODs might play an important role in xylem, leaf, root and flower. Furthermore, under low temperature conditions, some BPPODs showed different expression patterns at different times.
\end{abstract}

Conclusions: The research on the structure and function of the POD genes in Betula pendula plays a very important role in understanding the growth and development process and the molecular mechanism of stress resistance. These results lay the theoretical foundation for the genetic improvement of Betula pendula.

Keywords: Betula pendula, Class III peroxidases, Phylogenetic analysis, Chromosomal location, Expression pattern

\section{Background}

Peroxidases or peroxide reductases (POD, EC number 1.11.1.x) are a large group of oxidases existing in animals, plants and microorganisms, which catalyzes the oxidation of a particular substrate by hydrogen peroxide [1]. Among them, class III peroxidases are plant specific oxidoreductases, which are extremely widespread presence in the plant kingdom [2]. The Class III peroxidase in plants are also reported as POX [3, 4], GPX [5], Prx [6], ClassIII PRX [7], and POD [8, 9]. Most plant species contain dozens of Class III peroxidases, for example, switchgrass [7] genome contains more than 200 POD coding genes, and Populus [10], rice and Arabidopsis

\footnotetext{
* Correspondence: chensunefu@163.com

${ }^{\dagger}$ Kewei Cai and Song Chen contributed equally to this work.

State Key Laboratory of Tree Genetics and Breeding, Northeast Forestry University, Harbin 150040, China
}

contain 93, 138 and 73 members of POD family, respectively $[6,11]$.

POD are secreted peroxidase derived from higher plants, participate in a variety of physiological processes in the whole plant life cycle [12]. Recent studies indicate that POD has two most important functions in plants: on the one hand, it is related to the normal morphogenesis of plants and plays a role in the growth and development of plants. On the other hand, it is related to the resistance of plants, including disease resistance, cold resistance, drought resistance, etc., and it is one of the important protective enzymes in plants $[13,14]$. Although it is known that POD play a key role in cell growth and response to abiotic stress, the specific function of each member of the family is still elusive. Therefore, it is very important to study the molecular mechanisms of POD in plant development and stress resistance [15].

(c) The Author(s). 2021 Open Access This article is licensed under a Creative Commons Attribution 4.0 International License, which permits use, sharing, adaptation, distribution and reproduction in any medium or format, as long as you give appropriate credit to the original author(s) and the source, provide a link to the Creative Commons licence, and indicate if changes were made. The images or other third party material in this article are included in the article's Creative Commons licence, unless indicated otherwise in a credit line to the material. If material is not included in the article's Creative Commons licence and your intended use is not permitted by statutory regulation or exceeds the permitted use, you will need to obtain permission directly from the copyright holder. To view a copy of this licence, visit http://creativecommons.org/licenses/by/4.0/ The Creative Commons Public Domain Dedication waiver (http://creativecommons.org/publicdomain/zero/1.0/) applies to the data made available in this article, unless otherwise stated in a credit line to the data. 
Gene family is a group of genes derived from the same ancestor, which are composed of two or more copies of a gene through gene doubling or duplication [16]. During the last decade, several molecular biology approaches have been developed to isolate, characterize and study the expression of $P O D$ gene family in plants [6]. Betula pendula is a pioneer boreal tree that can be induced to flower within 1 year [17], it plays an important role in people life $[18,19]$. However, so far, there has been no report about the $P O D$ gene family in $B$. pendula. It has been shown that POD is related to the synthesis of lignin [20] and cork [21, 22], and lignin is considered as an important defense means against invasion and expansion of pathogens $[23,24]$. At the same time, a large number of experimental evidences of stress treatment showed that under the stress of drought and low temperature, the expression of POD increased significantly [25, 26].

Since Betula pendula is a widespread species and has many applications in the pulp and paper industry, it is necessary to study its development and physiology [27]. Understanding the role of POD family in lignin synthesis and resistance to biotic and abiotic stresses in $B$. pen$d u l a$, it will contribute to its application in industrial production [28]. Fortunately, with the completion of the whole genome sequencing of $B$. pendula $[29,30]$, bioinformatics analysis of the $P O D$ gene family in $B$. pendula at the genome level has become possible.

In the study, we used bioinformatics methods to identify $P O D$ gene family members in $B$. pendula from the genomic level, and analyzed their protein physical and chemical properties, subcellular localization, evolutionary relationship, conserved motifs and other information [31]. Our study provides important insights for further study of the potential role of $P O D$ gene family in $B$. pendula growth and development.

\section{Results}

\section{Identification of $P O D$ genes}

To identify members of $P O D$ family in $B$. pendula, we used the 73 POD genes of Arabidopsis to obtain the best hits in the B. pendula genome by BLASTP. A total of 90 putative $P O D s$ were identified in the $B$. pendula genome. We further examined the conserved domains of proteins encoded by these genes using Pfam [32] and SMART [33] databases. The results revealed that all the genes have classical $P O D$ domain structures, which demonstrate the reliability of the results. The $B$. pendula genome contains more PODs than Arabidopsis (73) [6], but fewer than Populus trichocarpa (93) [34], Pyrus bretschneideri (94) [31], and rice (138) [11]. We defined the $B p P O D s$ as BpPOD1 to BpPOD90. The isoelectric points (PI) ranged from 4.28 to 9.6, and 46 POD proteins were greater than 7.5. In addition, subcellular locations of these $B p P O D s$ are mainly in the cytoplasm, cell membrane, vacuole, chloroplast and nucleus. The subcellular location, molecular weight (MW) and other information of each $B P P O D$ genes was listed in Table 1.

\section{Phylogenetic analyses of $P O D$ gene family in $B$. pendula} To investigate the evolutionary relationships, we performed multiple sequence alignment of $P O D$ family genes in B. pendula and Arabidopsis, and constructed the phylogenetic tree by MEGA 7.0 software (Fig. 1). The BpPOD proteins were classified into 12 groups with high bootstrap probabilities, designated group I to group XII. The POD genes of each subgroup is unevenly distributed, with the number of members varies from 4 to 15. Subgroup VIII contains the most members (15), subgroup X, XI, XII contains the least number of members, with only 4 members.

\section{Gene structures}

To understand the structural diversity of the $P O D$ genes, exon-intron analysis was performed in BPPODs (Fig. 2). The result reveals several variations, in terms of the number of introns, BpPODs contains one to six introns, and some members contain three introns. Noteworthy, there were no introns in five BpPODs (BpPOD9, BpPOD11, BpPOD16, BpPOD57 and BpPOD61). In addition, $B p P O D 76$ and $B p P O D 87$ have the most introns (6), followed by BpPOD24 and BpPOD51 (5). Moreover, we found that the genes of the same group are similar in gene structure. For example, BpPOD20, BpPOD22 and $B p P O D 82$ have three exons and two intron, both of which belong to Group V; BpPOD73 and BpPOD74 have two exons and one intron, both of which belong to Group XI [35].

\section{Analysis of conserved amino acid motifs}

To understand the functional regions of BpPODs, conserved amino acid motifs analyses of BPPOD proteins were performed. A total of eight conserved amino acid motifs were identified in the BpPOD proteins (Fig. 3). All BpPOD proteins contain at least one conserved amino acid motif. For example, BpPOD55 only contains motif 8, BpPOD83 contains motif 1 and 7, while BpPOD10 proteins contain all the eight conserved amino acid motifs.

The conserved motifs of POD proteins clustered in the same group are similar in composition, indicating that these members have close evolutionary relationships [36]. In addition, most members of BpPOD proteins contain motif 1 , motif 2 , motif 3 , motif 4 and other conserved motifs, these motifs might play an important role in BpPOD proteins. 
Table 1 The 90 POD genes identified in B. pendula and their sequence characteristics

\begin{tabular}{|c|c|c|c|c|}
\hline Protein Name & Gene ID & Theoretical pl & Molecular weight (Da) & Subcellular localization \\
\hline BpPOD1 & Bpev01.c0000.g0142 & 7.16 & $38,520.2$ & Vacuole \\
\hline BpPOD2 & Bpev01.c0001.g0018 & 5.76 & $34,481.79$ & Cytoplasm \\
\hline BpPOD3 & Bpev01.c0015.g0107 & 8.52 & $35,715.62$ & Cytoplasm \\
\hline BpPOD4 & Bpev01.c0015.g0108 & 9.06 & $35,517.27$ & Cytoplasm \\
\hline BpPOD5 & Bpev01.c0022.g0082 & 8.05 & $34,206.63$ & Cytoplasm \\
\hline BpPOD6 & Bpev01.c0022.g0083 & 9.11 & $34,146.78$ & Cytoplasm \\
\hline BpPOD7 & Bpev01.c0023.g0043 & 9.32 & $36,436.39$ & Cytoplasm \\
\hline BpPOD8 & Bpev01.c0027.g0161 & 6.43 & $35,985.96$ & Cytoplasm \\
\hline BpPOD9 & Bpev01.c0038.g0066 & 8.86 & $16,650.95$ & Cytoplasm \\
\hline BpPOD10 & Bpev01.c0055.g0011 & 5.7 & $36,849.2$ & Cytoplasm \\
\hline BpPOD11 & Bpev01.c0090.g0013 & 9.15 & $40,130.67$ & Cytoplasm \\
\hline BpPOD12 & Bpev01.c0090.g0014 & 8.72 & $35,448.63$ & Cytoplasm \\
\hline BpPOD13 & Bpev01.c0090.g0016 & 8.9 & $35,155.75$ & Cytoplasm \\
\hline BpPOD14 & Bpev01.c0090.g0017 & 9.03 & $34,839.38$ & Cytoplasm \\
\hline BpPOD15 & Bpev01.c0090.g0018 & 9.21 & $34,931.7$ & Cytoplasm \\
\hline BpPOD16 & Bpev01.c0094.g0039 & 7.57 & $35,824.75$ & Cytoplasm \\
\hline BpPOD17 & Bpev01.c0115.g0033 & 8.28 & $34,790.11$ & Cytoplasm \\
\hline BpPOD18 & Bpev01.c0115.g0034 & 9.21 & $34,709.95$ & Cytoplasm \\
\hline BpPOD19 & Bpev01.c0115.g0036 & 9.57 & $34,410.61$ & Cytoplasm \\
\hline BpPOD20 & Bpev01.c0115.g0100 & 8.13 & $28,980.85$ & Cytoplasm \\
\hline BpPOD21 & Bpev01.c0127.g0079 & 8.51 & $37,428.88$ & Cytoplasm \\
\hline BpPOD22 & Bpev01.c0154.g0008 & 6.98 & $34,749.39$ & Cytoplasm \\
\hline BpPOD23 & Bpev01.c0154.g0009 & 5.97 & $34,913.58$ & Cytoplasm \\
\hline BpPOD24 & Bpev01.c0154.g0011 & 6.17 & $38,375.7$ & Cytoplasm \\
\hline BpPOD25 & Bpev01.c0154.g0012 & 5.71 & $34,090.42$ & Cytoplasm \\
\hline BpPOD26 & Bpev01.c0154.g0013 & 8.56 & $33,988.06$ & Cytoplasm \\
\hline BpPOD27 & Bpev01.c0154.g0014 & 4.92 & $30,751.05$ & Cytoplasm \\
\hline BpPOD28 & Bpev01.c0154.g0015 & 5.79 & $33,695.64$ & Cytoplasm \\
\hline BpPOD29 & Bpev01.c0154.g0016 & 9.09 & $37,699.91$ & Cytoplasm \\
\hline BpPOD30 & Bpev01.c0161.g0034 & 6.95 & $37,831.82$ & Cytoplasm \\
\hline BpPOD31 & Bpev01.c0210.g0047 & 8.01 & $35,734.78$ & Cytoplasm \\
\hline BpPOD32 & Bpev01.c0214.g0014 & 4.7 & $44,989.41$ & Cytoplasm \\
\hline BpPOD33 & Bpev01.c0222.g0007 & 6.09 & $36,320.35$ & Cytoplasm \\
\hline BpPOD34 & Bpev01.c0228.g0001 & 6.29 & $25,755.32$ & Chloroplast \\
\hline BpPOD35 & Bpev01.c0253.g0021 & 6.31 & $33,855.45$ & Cytoplasm \\
\hline BpPOD36 & Bpev01.c0253.g0022 & 4.75 & $35,040.89$ & Vacuole \\
\hline BpPOD37 & Bpev01.c0253.g0025 & 4.28 & $36,363.54$ & Vacuole \\
\hline BpPOD38 & Bpev01.c0253.g0026 & 4.8 & $36,734.26$ & Vacuole \\
\hline BpPOD39 & Bpev01.c0292.g0023 & 6.75 & $35,088.84$ & Cytoplasm \\
\hline BpPOD40 & Bpev01.c0335.g0033 & 5.16 & $37,438.99$ & Cytoplasm \\
\hline BpPOD41 & Bpev01.c0395.g0053 & 4.8 & $34,822.54$ & Vacuole \\
\hline BpPOD42 & Bpev01.c0414.g0013 & 9.23 & $35,888.05$ & Cytoplasm \\
\hline BpPOD43 & Bpev01.c0441.g0005 & 7.52 & $35,297.73$ & Cytoplasm \\
\hline BpPOD44 & Bpev01.c0443.g0013 & 6.51 & $37,358.81$ & Cytoplasm \\
\hline
\end{tabular}


Table 1 The 90 POD genes identified in B. pendula and their sequence characteristics (Continued)

\begin{tabular}{|c|c|c|c|c|}
\hline Protein Name & Gene ID & Theoretical pl & Molecular weight (Da) & Subcellular localization \\
\hline BpPOD45 & Bpev01.c0483.g0021 & 5.6 & $36,858.73$ & Cytoplasm \\
\hline BpPOD46 & Bpev01.c0518.g0009 & 6.34 & $35,401.21$ & Cytoplasm \\
\hline BpPOD47 & Bpev01.c0518.g0010 & 6.22 & $35,012.98$ & Cytoplasm \\
\hline BpPOD48 & Bpev01.c0566.g0037 & 4.74 & $35,256.87$ & Cytoplasm \\
\hline BpPOD49 & Bpev01.c0577.g0019 & 8.86 & $33,926.77$ & Cytoplasm \\
\hline BpPOD50 & Bpev01.c0605.g0023 & 5.58 & $37,438.76$ & Cytoplasm \\
\hline BpPOD51 & Bpev01.c0605.g0024 & 5.92 & $40,256.6$ & Cytoplasm \\
\hline BpPOD52 & Bpev01.c0672.g0007 & 5.31 & $35,421.93$ & Cytoplasm \\
\hline BpPOD53 & Bpev01.c0702.g0001 & 8.28 & $41,401.42$ & Cytoplasm \\
\hline BpPOD54 & Bpev01.c0753.g0001 & 5.97 & $23,067.41$ & Cytoplasm \\
\hline BpPOD55 & Bpev01.c0811.g0007 & 8.7 & 9122.73 & Cell membrane \\
\hline BpPOD56 & Bpev01.c0834.g0015 & 7.95 & $37,636.09$ & Cytoplasm \\
\hline BpPOD57 & Bpev01.c0848.g0029 & 8.46 & $36,912.4$ & Cytoplasm \\
\hline BpPOD58 & Bpev01.c0932.g0013 & 4.69 & $34,485.93$ & Cytoplasm \\
\hline BpPOD59 & Bpev01.c0944.g0009 & 9.6 & $35,965.28$ & Cytoplasm \\
\hline BpPOD60 & Bpev01.c0990.g0011 & 8.86 & $34,411.46$ & Cytoplasm \\
\hline BpPOD61 & Bpev01.c0991.g0009 & 9.37 & $16,644.16$ & Cytoplasm \\
\hline BpPOD62 & Bpev01.c1029.g0016 & 4.71 & $38,697.61$ & Cytoplasm \\
\hline BpPOD63 & Bpev01.c1029.g0017 & 5.2 & $38,867.05$ & Cytoplasm \\
\hline BpPOD64 & Bpev01.c1078.g0006 & 5.67 & $17,097.87$ & Cell membrane \\
\hline BpPOD65 & Bpev01.c1163.g0010 & 8.1 & $36,508.06$ & Cytoplasm \\
\hline BpPOD66 & Bpev01.c1189.g0010 & 6.93 & $35,457.58$ & Cytoplasm \\
\hline BpPOD67 & Bpev01.c1189.g0011 & 5.94 & $28,953.96$ & Cytoplasm \\
\hline BpPOD68 & Bpev01.c1230.g0004 & 6.41 & $57,999.02$ & Cytoplasm \\
\hline BpPOD69 & Bpev01.c1230.g0005 & 8.95 & $37,658.16$ & Cytoplasm \\
\hline BpPOD70 & Bpev01.c1519.g0002 & 6.99 & $35,815.14$ & Cytoplasm \\
\hline BpPOD71 & Bpev01.c1529.g0006 & 8.89 & $38,531.35$ & Cytoplasm \\
\hline BpPOD72 & Bpev01.c1719.g0005 & 8.42 & $33,743.46$ & Cytoplasm \\
\hline BpPOD73 & Bpev01.c1776.g0001 & 8.38 & $33,425.87$ & Cytoplasm \\
\hline BpPOD74 & Bpev01.c1776.g0002 & 6.44 & $28,814.32$ & Cytoplasm \\
\hline BpPOD75 & Bpev01.c1889.g0001 & 8.46 & $32,601.89$ & Cytoplasm \\
\hline BpPOD76 & Bpev01.c1889.g0002 & 8.75 & $43,372.13$ & Cytoplasm \\
\hline BpPOD77 & Bpev01.c1889.g0003 & 8.05 & $33,592.04$ & Cytoplasm \\
\hline BpPOD78 & Bpev01.c1922.g0001 & 8.42 & $34,940.65$ & Cytoplasm \\
\hline BpPOD79 & Bpev01.c1922.g0002 & 9.41 & $32,305.51$ & Cytoplasm \\
\hline BpPOD80 & Bpev01.c2035.g0001 & 5.3 & $20,474.83$ & Chloroplast \\
\hline BpPOD81 & Bpev01.c2059.g0007 & 7.56 & $34,908.57$ & Cytoplasm \\
\hline BpPOD82 & Bpev01.c2165.g0002 & 6.38 & $34,883.46$ & Cytoplasm \\
\hline BpPOD83 & Bpev01.c2185.g0001 & 5.01 & 14,822 & Nucleus \\
\hline BpPOD84 & Bpev01.c2220.g0001 & 9.04 & $29,887.06$ & Cytoplasm \\
\hline BpPOD85 & Bpev01.c2322.g0001 & 9.35 & $35,748.32$ & Cytoplasm \\
\hline BpPOD86 & Bpev01.c3133.g0001 & 6.89 & 9127.53 & Nucleus \\
\hline BpPOD87 & Bpev01.c3133.g0002 & 7.89 & $61,365.35$ & Cytoplasm \\
\hline BpPOD88 & Bpev01.c3139.g0001 & 8.54 & $34,756.42$ & Cytoplasm \\
\hline
\end{tabular}


Table 1 The 90 POD genes identified in B. pendula and their sequence characteristics (Continued)

\begin{tabular}{lllll}
\hline Protein Name & Gene ID & Theoretical pl & Molecular weight (Da) & Subcellular localization \\
\hline BpPOD89 & Bpev01.c3210.g0001 & 8.53 & $33,682.38$ & Cytoplasm \\
BpPOD90 & Bpev01.c3916.90001 & 4.74 & $38,628.55$ & Cytoplasm \\
\hline
\end{tabular}

\section{Chromosomal location and evolution analysis of BPPODs}

Based on the genomic information of $B$. pendula, we analyzed the chromosomal distribution of 90 BpPODs. Chromosome localization analysis showed that the 90 $B p P O D s$ were unevenly distributed on 14 chromosomes (Fig. 4). Chromosome 1 and 8 contains the most BpPODs (14), followed by chromosome 13 (10). There are eight $B p P O D s$ on chromosome 5 and chromosome 7 , and only one BpPODs on chromosome 14. Noteworthy, there is no $P O D$ gene distribution on chromosome 11. We also found that the relatively high density of BpPODs on chromosome 13 and chromosome 8.

Gene duplication, including segmental and tandem duplication, is considered to be one of the primary driving forces in the evolution of genomes $[37,38]$. In this study, among the $90 \mathrm{BPPODs}$ identified, a large number of $B p P O D s$ have the same duplicated regions (Fig. 5). In general, gene tandem duplication is one of the basic reasons for the formation of gene clusters [39]. In this study, we found that some $B P P O D s$ were adjacent to each other (Fig. 4). For instance, BpPOD17-20 on

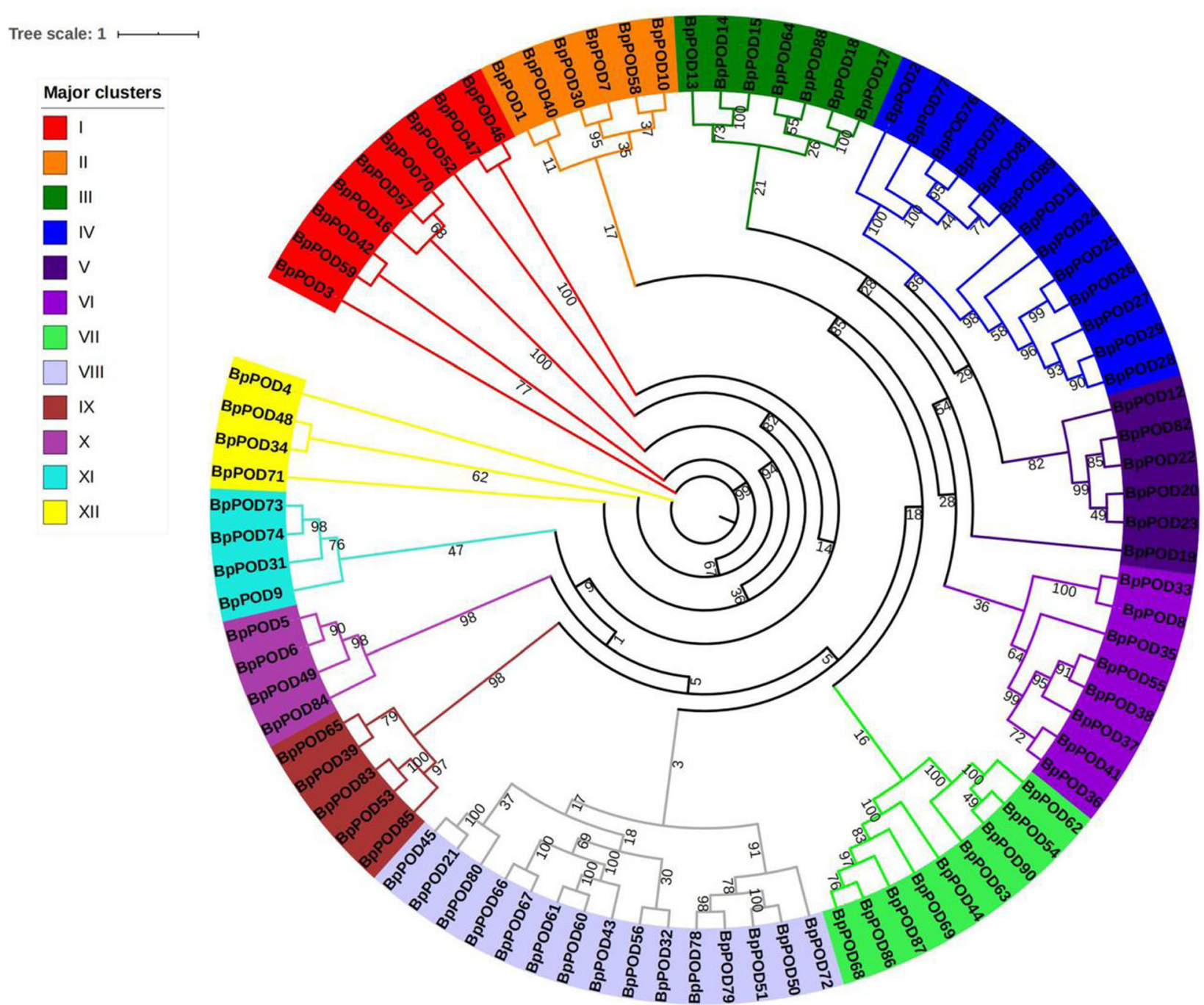

Fig. 1 Phylogenetic analysis of POD family genes from B. pendula. According to phylogenetic relationships, 90 BpPOD genes were classified into 12 subgroups (subgroups I to XII). The phylogenetic tree was constructed using MEGA 7.0 with the maximum likelihood (ML) method 


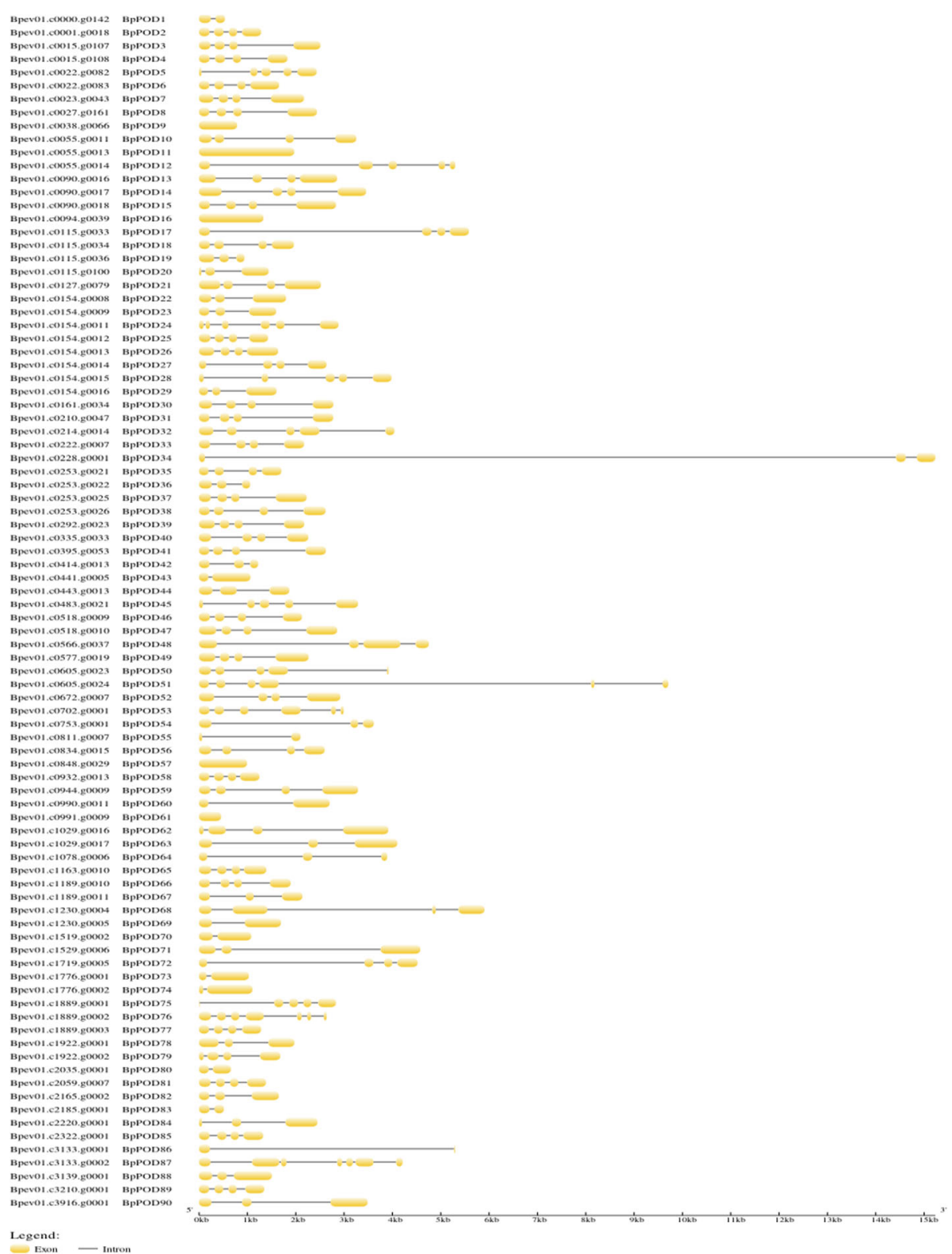

Fig. 2 Gene structure analyses of BPPOD genes. The exons and introns are indicated by yellow cylinder bars and black lines, respectively. The scale at the bottom of the figure is in kilobases. Gene structure was visualized by Gene Structure Display Server (GSDS)

chromosome 5, BpPOD22-29 on chromosome 8, and $B p P O D 11-15$ on chromosome 13 were tandemly linked together, implying that tandem duplication relationships may exist between these BpPODs [40]. The result indicated that tandem duplications play main contributors in the expansion of the $B P P O D$ gene family. The result was consistent with Populus trichocarpa POD gene family, tandem duplications also contributed significantly to the expansion of POD gene family in Populus trichocarpa [34]. However, in previous studies, many species also have produced some different results. For example, in the report on the $P O D$ gene family of pear, it was found that segmental duplication was the main reason for the extension of the POD family [31]. In the maize, segmental and tandem duplication affect the extension of maize $P O D$ gene family [36]. These results indicate that there are significant differences in the $P O D$ genes expansion pattern in $B$. pendula, maize and Chinese pear, which suggested that $P O D$ gene family have different expansion patterns among different species.

Considering the selection pressures of the BPPOD duplicated genes, $\mathrm{Ka}, \mathrm{Ks}$, and $\mathrm{Ka} / \mathrm{Ks}$ ratios were calculated for the 23gene pairs (Table 2). In the process of evolution, $\mathrm{Ka} / \mathrm{Ks}>1$ represents positive selection, $\mathrm{Ka} / \mathrm{Ks}=1$ 


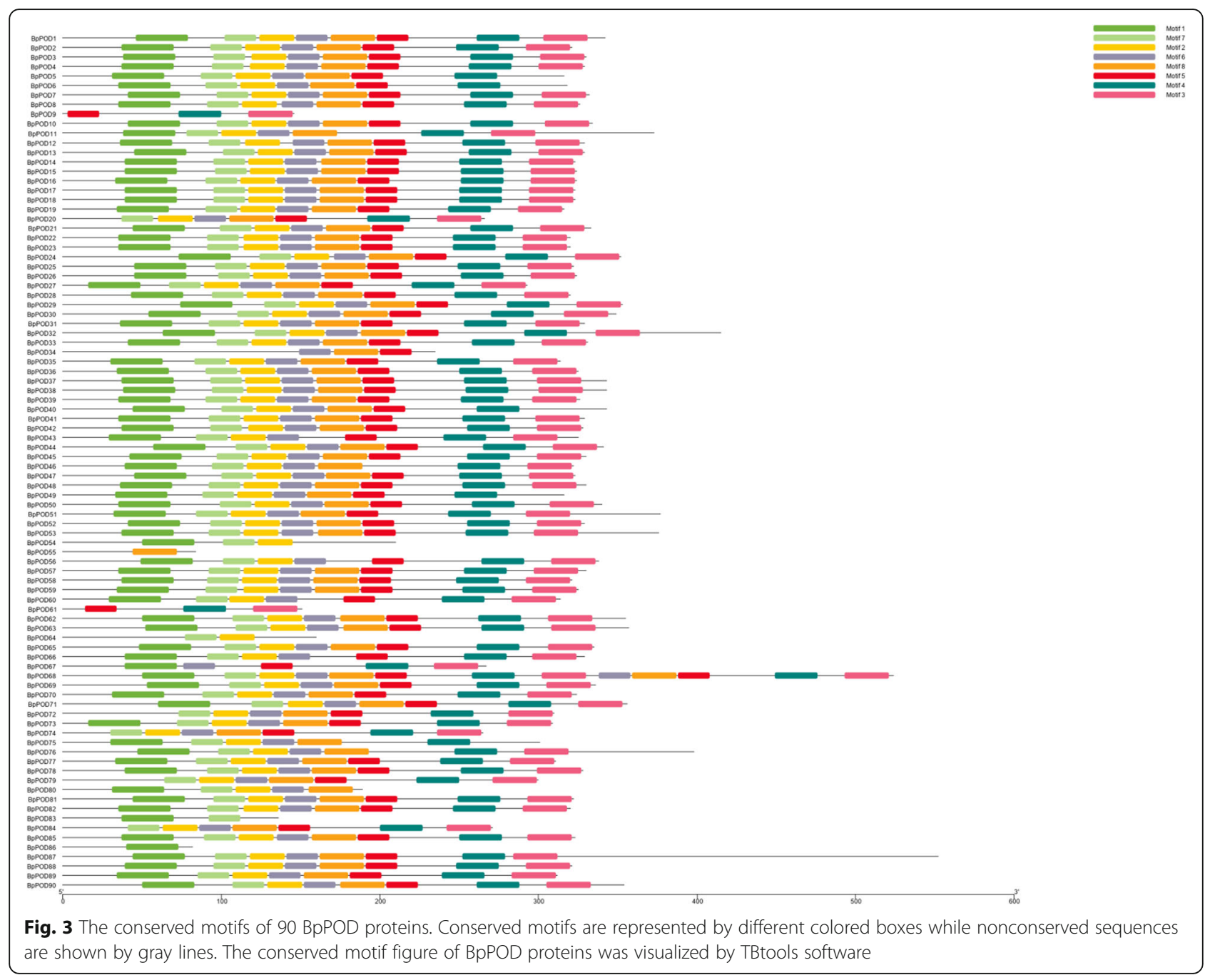

represents neutral selection and $\mathrm{Ka} / \mathrm{Ks}<1$ represents negative selection [35]. $\mathrm{Ka} / \mathrm{Ks}$ analysis showed that the $\mathrm{Ka} / \mathrm{Ks}$ value of most $B P P O D$ gene pairs were less than 1 , indicating that these genes underwent negative selection and were relatively conservative in evolution, with relatively stable structure and consistent function.

To analyze the evolution of BPPODs family, we created the comparative syntenic diagram of the birch and three representative species (Fig. 6; Tables 3, 4 and 5). The results showed that the number of orthologous pairs between B. pendula and Arabidopsis thaliana, Populus trichocarpa and Vitis vinifera were 17, 49 and 43, respectively. In these gene pairs, some $B p P O D$ genes (BpPOD3, BpPOD7, BpPOD16, BpPOD21, BpPOD40, BpPOD4, BpPOD48, BpPOD52, BpPOD57 and $B P P O D 84)$ were indicated to have collinear relationships with three species. Interestingly, two or more $P O D$ genes from Arabidopsis thaliana, Populus trichocarpa and Vitis vinifera matched one birch $P O D$ gene, these genes may play a more important role than other genes in
$B p P O D$ family. For example, AT1G24110.1.TAIR10, AT3G28200.1.TAIR10 and AT5G40150.1.TAIR10 are orthologous to BpPOD16, Potri.006G107000.1.v4.1 and Potri.016G132800.1.v4.1 are orthologous to BpPOD22, VIT_206s0004g01180.1 and VIT_208s0007g06650.1 are orthologous to BpPOD41 (Tables 3, 4 and 5).

\section{Tissue-specific expression of $B p P O D s$}

To explore the functions of $P O D$ genes in Betula platyphylla $\times$ Betula pendula, the expression profiles in different tissues (including root, xylem, young leaf and flower) were investigated with available experimental data. Of the $90 \mathrm{BPPODs}, 69$ genes were expressed in one or more birch tissues, while $21 \mathrm{BpPOD}$ genes were not expressed in different tissues (Relative expression value $>0$ as basal expression) [41]. As shown in Fig. 7, most $B p P O D s$ were expressed preferentially in different tissues. For example, BpPOD6, BpPOD21 and BpPOD37 were highly expressed in xylem. Several BpPODs were expressed in root during development, such as 


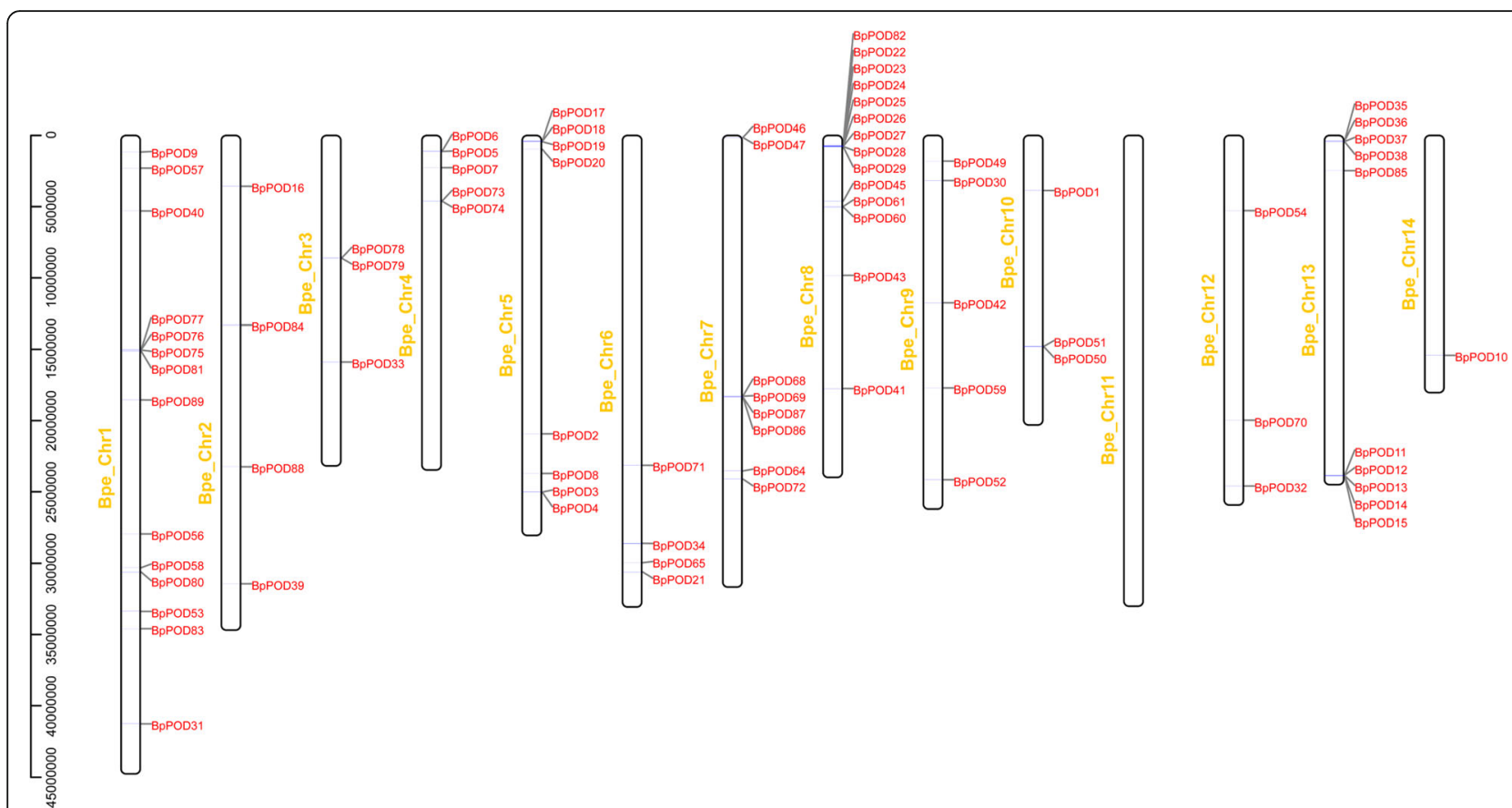

Fig. 4 Chromosomal locations of 90 POD genes on 14 B. pendula chromosomes. The number of chromosomes (chr01-chr14) is marked in yellow, and each $P O D$ gene is marked in red. The gene names on the right side of each chromosome correspond to the approximate locations of each $P O D$ gene. The chromosome location figure of BPPODs was constructed by TBtools software

BpPOD62, BpPOD63 and BpPOD65. BpPOD78 and $B p P O D 19$ showed higher expression levels in young leaf and flower, respectively. The expression level of BpPOD6 was high in xylem and low in root, leaf and flower. In contrast, BpPOD67, BpPOD68, BpPOD80 and BpPOD81 had no expression in any of the investigated tissues. $B p P O D 21, B P P O D 59$ and BpPOD62 were highly expressed in developing xylem, root, leaf and flower. In conclusion, the expression changes of BpPODs in these tissues indicated that $P O D$ genes played an important role in the growth and development of B. pendula.

\section{Responses of $B p P O D s$ expression to cold treatment}

POD participates in a variety of physiological processes in the plant, and especially in resisting various stresses play an important role [42]. In recent years, many scholars have investigated the performance of $P O D$ genes in response to abiotic stress [36]. For example, Arabidopsis overexpressing AtPOD3 showed an increase in dehydration and salt tolerance, whereas the antisense suppression of AtPOD3 exhibited dehydration and salt sensitive phenotypes [43]. In this study, we examined the expression levels of the BpPODs in response to low temperature stress. As shown in Fig. 8, the result indicated that the expression of $B p P O D s$ was altered under cold treatment, some of BPPODs are induced but most of them not or slightly induced. After cold treatment, the expression levels of BpPOD4, BpPOD13, BpPOD15,
$B p P O D 17$ and $B p P O D 21$ were significantly induced at a relatively early stage $(0.5 \mathrm{~h}$ after treatment), and with the increase of cold treatment time, the relative expression level of these genes was also at a high level. The Fig. 8 shows that the expression levels of BpPOD19, BpPOD21, $B P P O D 39$ and $B P P O D 47$ were increased after $1.5 \mathrm{~h}$ treatment of low temperature. BpPOD50 and BpPOD58 did not respond to cold treatment at the beginning $(0.5 \mathrm{~h})$, and were slightly increased after $2 \mathrm{~h}$ exposure to low temperature. In addition, other genes are also induced by cold stress, such as BpPOD14, BpPOD16, BpPOD59, etc. In general, the $B p P O D s$ may play important roles in birch under cold stress.

\section{Validation of transcriptome data by qRT-qPCR analysis}

To verify the accuracy of the RNA-Seq data under cold treatment $\left(6^{\circ} \mathrm{C}\right)$ in $B$. pendula, six randomly selected $B p P O D s$ were tested for Quantitative real-time PCR (qRT-PCR). The expression pattern of six BpPODs using qRT-qPCR were in accordance with that detected by RNA-seq (Fig. 9). BpPODs including BpPOD15, $B p P O D 47$ and BpPOD49 showed the highest transcript level when exposed to a low temperature for $1.5 \mathrm{~h}$. $B p P O D 4, B p P O D 17$ and BpPOD26 showed the highest transcript level at $3 \mathrm{~h}$. In general, all the results indicated that the expression profile results of RNA-seq were reliable. 


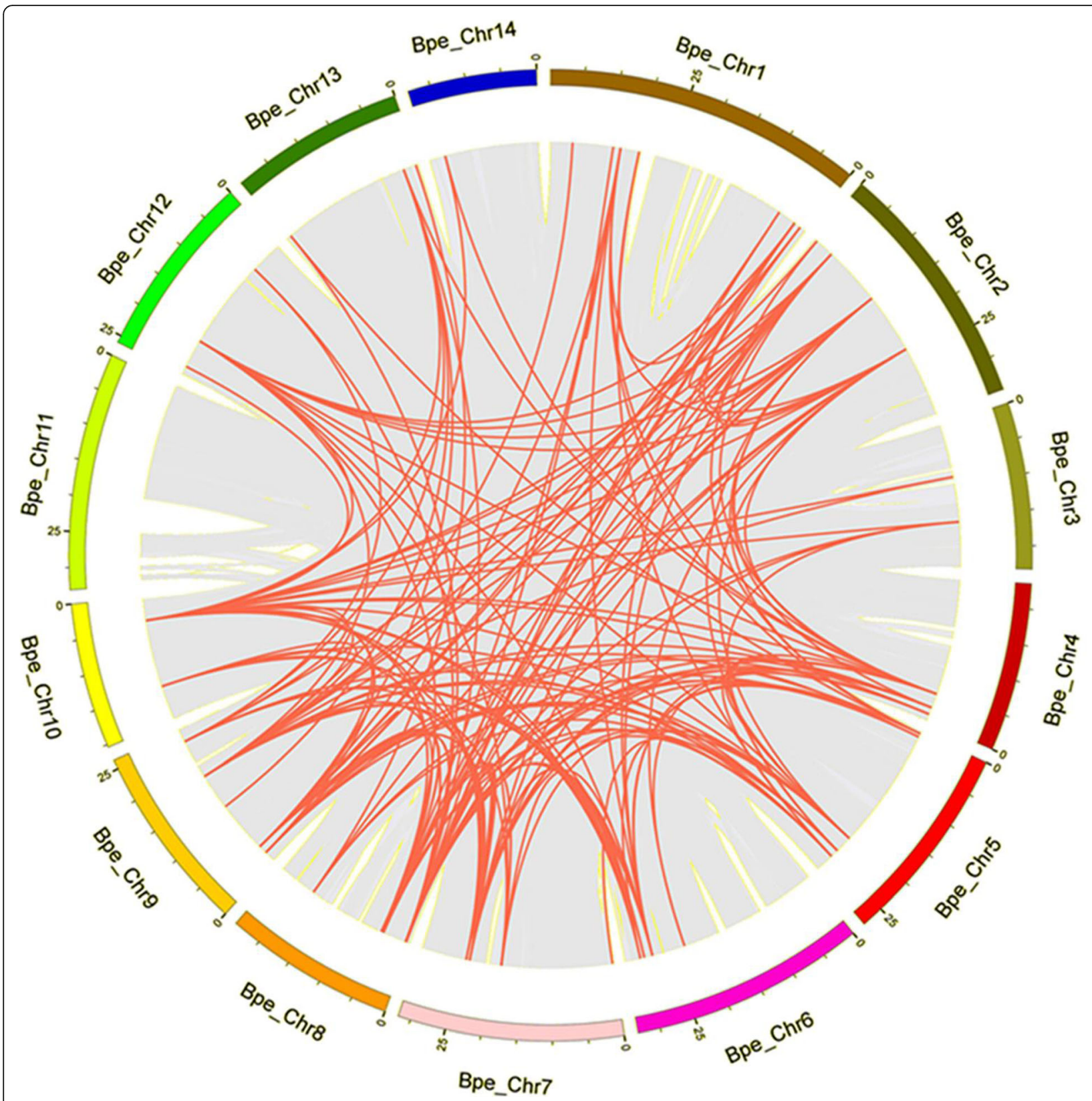

Fig. 5 BPPODs genomic distribution and collinear relationships. A total of 90 BpPODs were disproportionately mapped on the Betula pendula linkage groups using TBtools software. Red lines represent all homologous blocks in Betula pendula genome

\section{Discussion}

It is reported that Class III Peroxidases participates in a variety of physiological processes in the plant $[6,34]$, and play a important role in biological and abiotic stress responses during plant development [36]. At present, $P O D$ gene family have been published for Arabidopsis thaliana [6], Populus trichocarpa [34], Zea mays [36] and Oryza sativa [11], but there are no reports on the identification and function of POD gene family in Betula pendula. Fortunately, with the completion of the complete genome sequence of $B$. pendula $[29,30]$, bioinformatics analysis of the $P O D$ gene family in $B$. pendula at the genome level has become possible.

In the present study, based on the genomic information of $B$. pendula, a total of $90 P O D$ gene family members were identified, the number of $P O D$ family members was higher than that of Arabidopsis (73), which was similar to that of Populus trichocarpa (93) and Pyrus bretschneideri (94). Subsequently, phylogenetic relationships, subcellular localization, conserved motifs, gene structure and other information were analyzed [44]. 
Table 2 The Ka, Ks, and $\mathrm{Ka} / \mathrm{Ks}$ values for the 23 gene pairs

\begin{tabular}{|c|c|c|c|c|}
\hline Paralogous pairs & Ka & Ks & $\mathrm{Ka} / \mathrm{Ks}$ & Negative selection \\
\hline BpPOD17-BpPOD18 & 0.069471117 & 0.268358877 & 0.258873928 & Yes \\
\hline BpPOD18-BpPOD20 & 0.362725757 & 2.627815477 & 0.138033192 & Yes \\
\hline BpPOD24-BpPOD25 & 0.263859296 & 0.521302694 & 0.506153717 & Yes \\
\hline BpPOD24-BpPOD26 & 0.238387956 & 0.604227441 & 0.394533482 & Yes \\
\hline BpPOD24-BpPOD27 & 0.180902743 & 0.42607505 & 0.424579525 & Yes \\
\hline BpPOD24-BpPOD28 & 0.215885332 & 0.570985748 & 0.37809233 & Yes \\
\hline BpPOD25-BpPOD26 & 0.069221668 & 0.226863803 & 0.305124339 & Yes \\
\hline BpPOD25-BpPOD27 & 0.103222209 & 0.340981758 & 0.302720619 & Yes \\
\hline BpPOD25-BpPOD28 & 0.178403774 & 0.484390738 & 0.368305503 & Yes \\
\hline BpPOD26-BpPOD27 & 0.081063342 & 0.4345943 & 0.186526474 & Yes \\
\hline BpPOD26-BpPOD28 & 0.137670156 & 0.465437767 & 0.295786387 & Yes \\
\hline BpPOD27-BpPOD28 & 0.052823689 & 0.216841185 & 0.243605425 & Yes \\
\hline BpPOD11-BpPOD12 & 0.493471639 & 1.939854071 & 0.254385959 & Yes \\
\hline BpPOD11-BpPOD14 & 0.380143832 & 3.143972492 & 0.120911946 & Yes \\
\hline BpPOD12-BpPOD14 & 0.375233519 & 3.645948628 & 0.102917939 & Yes \\
\hline BpPOD12-BpPOD15 & 0.386625798 & 3.001334218 & 0.128817976 & Yes \\
\hline BpPOD13-BpPOD14 & 0.193518905 & 0.467304328 & 0.414117511 & Yes \\
\hline BpPOD13-BpPOD15 & 0.213861204 & 0.549200628 & 0.389404514 & Yes \\
\hline BpPOD14-BpPOD15 & 0.098858095 & 0.305317793 & 0.323787532 & Yes \\
\hline BpPOD22-BpPOD23 & 0.042284565 & 0.18631819 & 0.226948131 & Yes \\
\hline BpPOD5-BpPOD6 & 0.128227162 & 0.183810398 & 0.697605596 & Yes \\
\hline BpPOD5-BpPOD7 & 0.615552629 & 2.238568932 & 0.274975954 & Yes \\
\hline BpPOD6-BpPOD7 & 0.622751118 & 2.444971397 & 0.254706914 & Yes \\
\hline
\end{tabular}

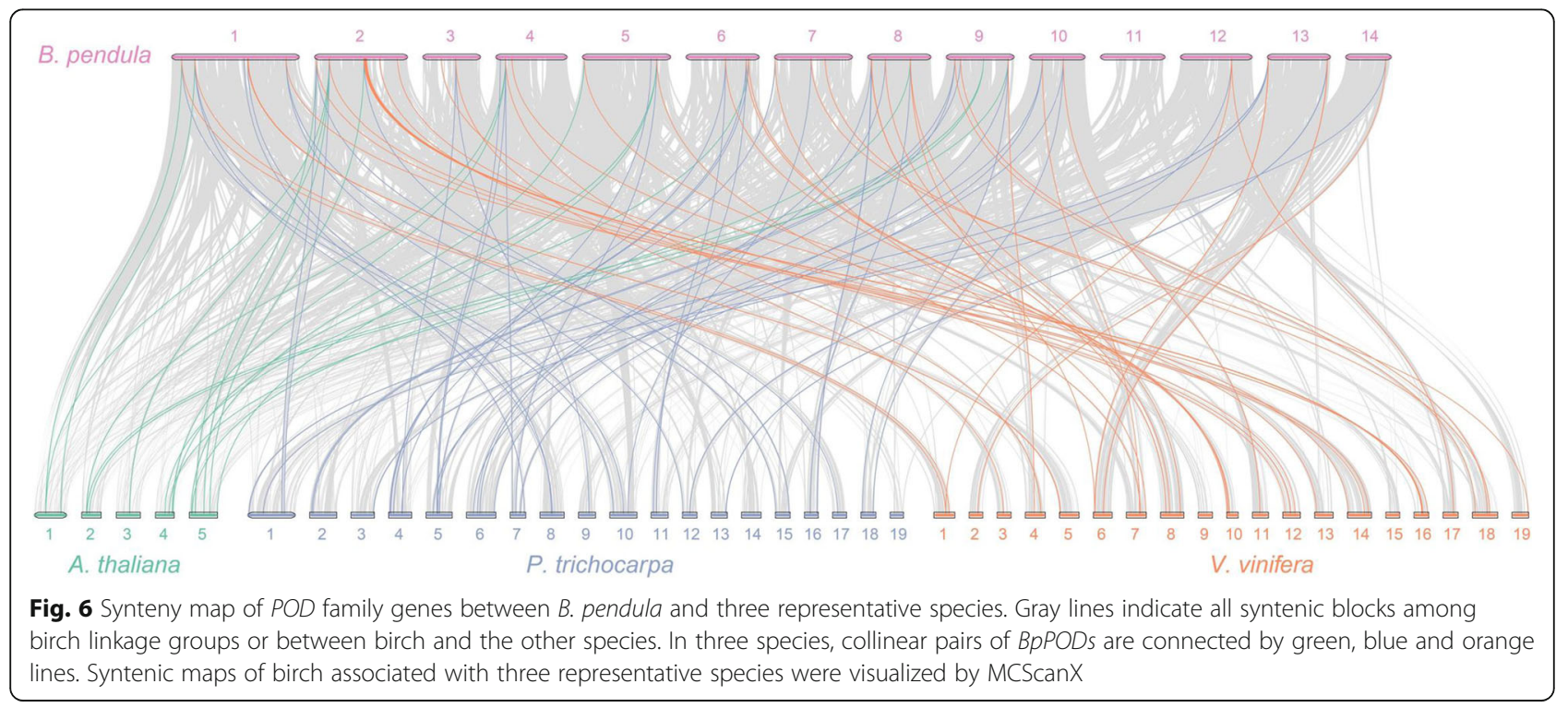


Table 3 Syntenic relationships of POD genes between Betula pendula and Arabidopsis thaliana

\begin{tabular}{lll}
\hline BpPOD gene name & BpPOD gene ID & AtPOD gene ID \\
\hline BpPOD3 & Bpev01.c0015.g0107.mRNA1 & AT4G37520.1.TAIR10 \\
BpPOD3 & Bpev01.c0015.g0107.mRNA1 & AT5G67400.1.TAIR10 \\
BpPOD7 & Bpev01.c0023.g0043.mRNA1 & AT2G18150.1.TAIR10 \\
BpPOD7 & Bpev01.c0023.g0043.mRNA1 & AT4G36430.1.TAIR10 \\
BpPOD16 & Bpev01.c0094.g0039.mRNA1 & AT1G24110.1.TAIR10 \\
BpPOD16 & Bpev01.c0094.g0039.mRNA1 & AT3G28200.1.TAIR10 \\
BpPOD16 & Bpev01.c0094.g0039.mRNA1 & AT5G40150.1.TAIR10 \\
BpPOD17 & Bpev01.c0115.g0033.mRNA1 & AT5G05340.1.TAIR10 \\
BpPOD21 & Bpev01.c0127.g0079.mRNA1 & AT4G21960.1.TAIR10 \\
BpPOD40 & Bpev01.c0335.g0033.mRNA1 & AT1G68850.1.TAIR10 \\
BpPOD41 & Bpev01.c0395.g0053.mRNA1 & AT5G06730.1.TAIR10 \\
BpPOD42 & Bpev01.c0414.g0013.mRNA1 & AT2G18980.1.TAIR10 \\
BpPOD42 & Bpev01.c0414.g0013.mRNA1 & AT4G30170.1.TAIR10 \\
BpPOD48 & Bpev01.c0566.g0037.mRNA1 & AT5G14130.1.TAIR10 \\
BpPOD52 & Bpev01.c0672.g0007.mRNA1 & AT2G24800.1.TAIR10 \\
BpPOD57 & Bpev01.c0848.g0029.mRNA1 & AT1G24110.1.TAIR10 \\
BpPOD84 & Bpev01.c2220.g0001.mRNA1 & AT5G51890.1.TAIR10 \\
\hline
\end{tabular}

In the process of genome evolution, gene duplication was the main factors that led to the expansion of gene family [38]. It has been reported that tandem duplication plays an important role in gene family extension in B. pendula [36]. For example, Chen, et al. found that tandem duplication is the main reason for the expansion of the NAC gene family in B. pendula [16]. However, in pears, segmental duplication is the main driver of gene family expansion [31]. Interestingly, in this study, we found that some $B p P O D$ s were adjacent to each other, suggesting tandem duplications play the major role in the evolution of the $B p P O D$ gene family. Noteworthy, segmental and tandem duplication contributed to the evolution of $P O D$ gene family in maize [36]. The results may be one of the reasons why the number of $P O D$ genes varies among different species. In addition, $\mathrm{Ka} /$ $\mathrm{Ks}$ analysis showed that the $\mathrm{Ka} / \mathrm{Ks}$ value of most $B p P O D$ gene pairs were less than 1 , indicating that these genes underwent negative selection. Furthermore, $B p P O D 5 /-6$, BpPOD24/- 25 and BpPOD24/- 27 gene pairs had higher $\mathrm{Ka} / \mathrm{Ks}$ values than other gene pairs, indicating that these genes evolved rapidly and had relatively stable structures. We also constructed the comparative syntenic maps of birch associated with Arabidopsis thaliana, Populus trichocarpa and Vitis vinifera. The results showed that there are 49 pairs of orthologous gene between birch and Populus trichocarpa, while the number of orthologous gene pairs (17) between Arabidopsis and birch is relatively small, which may be due to the genetic relationship between Populus trichocarpa and birch is close, but the relationship with Arabidopsis is far away.
In the study, the 90 BpPOD proteins possess ten highly conserved motifs. In addition, we found that the number and type of conserved motifs in 90 BpPOD proteins were slightly different. Notably, most BpPOD proteins contain all the conserved motifs, while only a few BpPOD proteins contain one or two motifs, which means that these motifs may be involved in the important basic function of the POD protein. The diversity of gene structure plays an important role in the evolution of gene families $[45,46]$. In this study, we performed the structure of $B p P O D$ genes. The results showed that 90 $B P P O D$ genes contained different number of exons and introns, and the characteristics of BpPODs from different subgroup were different. These results indicated that the POD gene family of $B$. pendula has great diversity. In addition, the study of gene structure also found that some $B p P O D s$ lack introns, which may be caused by a specific pathway [10, 47].

RNA-seq is usually used to study the mRNA expression amount of specific tissue or cells transcribed during a certain period of time, and then to analyze the related genes and phenotypes [48]. In this study, we used the acquired transcriptome data to investigate the function of BpPODs. RNA-Seq analysis of different tissues found that different $B p P O D s$ have tissue expression specificity, indicating that $B p P O D s$ had diverse functions. We found that of the $90 \mathrm{BpPODs}$, the most abundant expression was in the root, followed by the xylem. The results showed that most of the expressed POD genes participated in the reproductive growth process. The highest expression levels of BpPOD6, BpPOD21 and BpPOD37 genes were found in xylem. The results implied that three genes may play an important role of xylem synthesis in B. pendula. BpPOD59 is most expressed in flowers and leaves, suggesting that it may be related to leaf spreading and flowering formation in $B$. pendula. In addition, some $B p P O D s$ were expressed in all tissues, implying that they may have important effects on the growth and development process in B. pendula. In conclusion, $P O D$ family genes play an important regulatory role in the growth and development of B. pendula.

Abiotic stresses such as drought, low temperature and high salinity are serious natural disasters in plants, which seriously affect the growth and development of plants [46]. Plants have established a series of signal transduction and regulation molecular mechanisms to improve their ability to cope with adversity stress $[49,50]$. A large number of experimental studies [36] on stress treatment showed that under the stress of low temperature and other conditions, $P O D$ genes expression increased significantly $[25,26]$. However, there are few studies on the response of $P O D$ genes to cold stress in $B$. pendula. Therefore, we studied the expression patterns of the BPPODs under cold treatment. The results suggested 
Table 4 Syntenic relationships of POD genes between Betula pendula and Populus trichocarpa

\begin{tabular}{|c|c|c|}
\hline BpPOD gene name & BpPOD gene ID & PtPOD gene ID \\
\hline BpPOD1 & Bpev01.c0000.g0142.mRNA1 & Potri.005G072800.1.v4.1 \\
\hline BpPOD1 & Bpev01.c0000.g0142.mRNA1 & Potri.007G096200.1.v4.1 \\
\hline BpPOD3 & Bpev01.c0015.g0107.mRNA1 & Potri.007G053400.1.v4.1 \\
\hline BpPOD5 & Bpev01.c0022.g0082.mRNA1 & Potri.005G108900.1.v4.1 \\
\hline BpPOD7 & Bpev01.c0023.g0043.mRNA1 & Potri.005G118700.1.v4.1 \\
\hline BpPOD7 & Bpev01.c0023.g0043.mRNA1 & Potri.007G019300.1.v4.1 \\
\hline BpPOD8 & Bpev01.c0027.g0161.mRNA1 & Potri.005G135300.1.v4.1 \\
\hline BpPOD10 & Bpev01.c0055.g0011.mRNA1 & Potri.001G145800.1.v4.1 \\
\hline BpPOD11 & Bpev01.c0090.g0013.mRNA1 & Potri.013G154400.1.v4.1 \\
\hline BpPOD12 & Bpev01.c0090.g0014.mRNA1 & Potri.013G156800.1.v4.1 \\
\hline BpPOD14 & Bpev01.c0090.g0017.mRNA2 & Potri.013G156400.2.v4.1 \\
\hline BpPOD16 & Bpev01.c0094.g0039.mRNA1 & Potri.001G351000.3.v4.1 \\
\hline BpPOD21 & Bpev01.c0127.g0079.mRNA1 & Potri.004G015300.2.v4.1 \\
\hline BpPOD22 & Bpev01.c0154.g0008.mRNA1 & Potri.006G107000.1.v4.1 \\
\hline BpPOD22 & Bpev01.c0154.g0008.mRNA1 & Potri.016G132800.1.v4.1 \\
\hline BpPOD28 & Bpev01.c0154.g0015.mRNA1 & Potri.016G132700.1.v4.1 \\
\hline BpPOD30 & Bpev01.c0161.g0034.mRNA1 & Potri.002G031200.1.v4.1 \\
\hline BpPOD31 & Bpev01.c0210.g0047.mRNA1 & Potri.012G006800.3.v4.1 \\
\hline BpPOD31 & Bpev01.c0210.g0047.mRNA1 & Potri.015G003500.1.v4.1 \\
\hline BpPOD33 & Bpev01.c0222.g0007.mRNA1 & Potri.004G144600.1.v4.1 \\
\hline BpPOD33 & Bpev01.c0222.g0007.mRNA1 & Potri.009G106400.2.v4.1 \\
\hline BpPOD35 & Bpev01.c0253.g0021.mRNA1 & Potri.003G214500.1.v4.1 \\
\hline BpPOD36 & Bpev01.c0253.g0022.mRNA1 & Potri.001G011500.1.v4.1 \\
\hline BpPOD38 & Bpev01.c0253.g0026.mRNA1 & Potri.001G011000.1.v4.1 \\
\hline BpPOD38 & Bpev01.c0253.g0026.mRNA1 & Potri.001G012901.1.v4.1 \\
\hline BpPOD38 & Bpev01.c0253.g0026.mRNA1 & Potri.003G214800.1.v4.1 \\
\hline BpPOD40 & Bpev01.c0335.g0033.mRNA1 & Potri.008G1 10600.2.v4.1 \\
\hline BpPOD40 & Bpev01.c0335.g0033.mRNA1 & Potri.010G134500.1.v4.1 \\
\hline BpPOD41 & Bpev01.c0395.g0053.mRNA1 & Potri.016G058200.1.v4.1 \\
\hline BpPOD45 & Bpev01.c0483.g0021.mRNA1 & Potri.006G129900.1.v4.1 \\
\hline BpPOD47 & Bpev01.c0518.g0010.mRNA1 & Potri.004G134800.1.v4.1 \\
\hline BpPOD48 & Bpev01.c0566.g0037.mRNA1 & Potri.001G329200.1.v4.1 \\
\hline BpPOD48 & Bpev01.c0566.g0037.mRNA1 & Potri.017G064100.1.v4.1 \\
\hline BpPOD49 & Bpev01.c0577.g0019.mRNA1 & Potri.002G018000.1.v4.1 \\
\hline BpPOD49 & Bpev01.c0577.g0019.mRNA1 & Potri.005G108900.1.v4.1 \\
\hline BpPOD51 & Bpev01.c0605.g0024.mRNA1 & Potri.006G069600.1.v4.1 \\
\hline BpPOD51 & Bpev01.c0605.g0024.mRNA1 & Potri.018G131600.1.v4.1 \\
\hline BpPOD52 & Bpev01.c0672.g0007.mRNA1 & Potri.006G267400.1.v4.1 \\
\hline BpPOD52 & Bpev01.c0672.g0007.mRNA1 & Potri.018G015500.1.v4.1 \\
\hline BpPOD56 & Bpev01.c0834.g0015.mRNA1 & Potri.007G132800.1.v4.1 \\
\hline BpPOD57 & Bpev01.c0848.g0029.mRNA1 & Potri.010G036100.1.v4.1 \\
\hline BpPOD58 & Bpev01.c0932.g0013.mRNA1 & Potri.008G103200.1.v4.1 \\
\hline BpPOD65 & Bpev01.c1163.g0010.mRNA1 & Potri.004G023200.1.v4.1 \\
\hline BpPOD65 & Bpev01.c1163.g0010.mRNA1 & Potri.011G027300.1.v4.1 \\
\hline
\end{tabular}


Table 4 Syntenic relationships of POD genes between Betula pendula and Populus trichocarpa (Continued)

\begin{tabular}{llr}
\hline BpPOD gene name & BpPOD gene ID & PtPOD gene ID \\
\hline BpPOD68 & Bpev01.c1230.g0004.mRNA1 & Potri.010G175100.1.v4.1 \\
BpPOD70 & Bpev01.c1519.g0002.mRNA1 & Potri.012G076500.1.v4.1 \\
BpPOD71 & Bpev01.c1529.g0006.mRNA1 & Potri.004G052100.1.v4.1 \\
BpPOD71 & Bpev01.c1529.g0006.mRNA1 & Potri.011G062300.1.v4.1 \\
BpPOD84 & Bpev01.c2220.g0001.mRNA1 & Potri.015G138300.1.v4.1 \\
\hline
\end{tabular}

that some of $B p P O D s$ are induced but most of them not or slightly induced. A small number of $B p P O D s$ were highly expressed at $0.5 \mathrm{~h}$ after treatment, and with the extension of time, the expression reached the highest level. This suggested that these genes may be important in the process of resistance to stress in B. pendula. By contrast, the expression level of BpPOD30 and BpPOD 8 gradually increased at $2 \mathrm{~h}$ after treatment, implying that these genes participated in the late reaction of cold treatment. In addition, the expression of a few BpPODs decreased under cold treatment, we speculate that these genes may also have defense and other specific functions in $B$. pendula. These results suggested that $B p P O D$ genes play an important regulatory role in the stress response.

\section{Conclusion}

In short, we identified $90 P O D$ genes in Betula pendula. According to phylogenetic relationships, these $P O D$ genes were classified into 12 groups. The BpPODs are distributed in different numbers on the 14 chromosomes. In addition, we identified eight conserved domains of BpPOD proteins. Finally, expression patterns analysis revealed that some $B p P O D s$ might play significant roles in root, xylem, leaf and flower. Furthermore, under low temperature conditions, some BpPODs showed different expression patterns at different times. In this study, a preliminary study was conducted on the $P O D$ genes in $B$. pendula, which laid a foundation for further research on the function of $P O D$ gene family in future.

\section{Methods}

\section{Identification of peroxidase genes in B. pendula}

To identify $B$. pendula peroxidase genes, the $B$. pendula genome sequences were downloaded from National Center for Biotechnology Information ((https:// genomevolution.org/CoGe/GenomeInfo.pl?gid=35079)).

We also downloaded all annotated POD proteins sequences of Arabidopsis from the TAIR database (http:// www.arabidopsis.org/). The POD family protein sequence of Arabidopsis thaliana was used as seed sequence, and the whole genome of $B$. pendula was searched by BLASTP. To verify the reliability of the results, all the acquired candidate sequences were examined for the presence of the POD domain using PFAM [51] and SMART [52]. Finally, all candidate POD sequences were compared by ClustalW [53] and redundant genes were manually checked and removed, and all non-redundant $P O D$ genes were used for further analysis. The theoretical molecular weights (MWs) and isoelectric points (pIs) of the BpPOD protein sequences were analyzed by the ExPASY PROTPARAM tools (http://web.expasy.org/protparam/) [54].

\section{Phylogenetic analyses of peroxidase genes in B. pendula}

To investigate the phylogenetic information of the peroxidase genes of B. pendula, an unrooted tree was constructed using amino acid sequences of the peroxidase genes. The MUSCLE with default parameters were used for multi-sequence alignment analysis [55]. Subsequently, The phylogenetic tree was constructed by using MEGA 7.0 software, which was constructed by neighbor-joining method and repeated 1000 times (Bootstrap: 1000). The phylogenetic tree was beautified and annotated by using the online tool ITOL (https:// itol.embl.de/).

\section{Gene structure and conserved motif analysis}

The CDS sequences of PODs were extracted from the genomic structure information (GFF) of the genome (https://genomevolution.org/CoGe/GenomeInfo.pl?gid= 35079), and the intron and exon structures were visually analyzed using Gene Structure Display Server [56]. MEME software was used to analyze the conserved motif of BpPOD proteins [57], and TBtools was used to draw the schematic diagram.

\section{Chromosomal localization and gene collinearity analysis}

According to BpPODs starting positions on the birch chromosomes, TBtools software was used to determine the chromosome location image of the BpPODs [58]. In addition, the rate of $\mathrm{Ka} / \mathrm{Ks}$ was calculated for the duplicated gene pairs by using TBtools [58]. For gene collinearity analysis, syntenic maps of birch associated with three representative species were visualized by MCScanX [59]. 
Table 5 Syntenic relationships of POD genes between Betula pendula and Vitis vinifera

\begin{tabular}{|c|c|c|}
\hline BpPOD gene name & BpPOD gene ID & VvPOD gene ID \\
\hline BpPOD1 & Bpev01.c0000.g0142.mRNA1 & VIT_207s0191g00050.1.v2.1 \\
\hline BpPOD3 & Bpev01.c0015.g0107.mRNA1 & VIT_207s0129g00360.1.V2.1 \\
\hline BpPOD7 & Bpev01.c0023.g0043.mRNA1 & VIT_204s0023g02570.1.v2.1 \\
\hline BpPOD10 & Bpev01.c0055.g0011.mRNA1 & VIT_202s0012g00540.1.v2.1 \\
\hline BpPOD11 & Bpev01.c0090.g0013.mRNA1 & VIT_206s0004g07740.1.v2.1 \\
\hline BpPOD12 & Bpev01.c0090.g0014.mRNA1 & VIT_206s0004g07750.1.v2.1 \\
\hline BpPOD14 & Bpev01.c0090.g0017.mRNA2 & VIT_206s0004g07770.1.v2.1 \\
\hline BpPOD16 & Bpev01.c0094.g0039.mRNA1 & VIT_214s0066g01850.1.v2.1 \\
\hline BpPOD17 & Bpev01.c0115.g0033.mRNA1 & VIT_213s0067g02360.1.v2.1 \\
\hline BpPOD21 & Bpev01.c0127.g0079.mRNA1 & VIT_210s0116g01780.1.v2.1 \\
\hline BpPOD22 & Bpev01.c0154.g0008.mRNA1 & VIT_208s0058g00990.1.v2.1 \\
\hline BpPOD28 & Bpev01.c0154.g0015.mRNA1 & VIT_208s0058g00970.1.v2.1 \\
\hline BpPOD30 & Bpev01.c0161.g0034.mRNA1 & VIT_218s0001g13110.1.v2.1 \\
\hline BpPOD31 & Bpev01.c0210.g0047.mRNA1 & VIT_216s0098g00820.1.v2.1 \\
\hline BpPOD33 & Bpev01.c0222.g0007.mRNA1 & VIT_203s0063g01040.1.v2.1 \\
\hline BpPOD35 & Bpev01.c0253.g0021.mRNA1 & VIT_206s0004g01240.2.v2.1 \\
\hline BpPOD36 & Bpev01.c0253.g0022.mRNA1 & VIT_206s0004g01190.1.v2.1 \\
\hline BpPOD38 & Bpev01.c0253.g0026.mRNA1 & VIT_206s0004g01180.1.v2.1 \\
\hline BpPOD39 & Bpev01.c0292.g0023.mRNA1 & VIT_212s0059g02420.1.v2.1 \\
\hline BpPOD40 & Bpev01.c0335.g0033.mRNA1 & VIT_201s0010g01090.1.V2.1 \\
\hline BpPOD41 & Bpev01.c0395.g0053.mRNA1 & VIT_206s0004g01180.1.v2.1 \\
\hline BpPOD41 & Bpev01.c0395.g0053.mRNA1 & VIT_208s0007g06650.1.v2.1 \\
\hline BpPOD45 & Bpev01.c0483.g0021.mRNA1 & VIT_208s0040g02200.1.v2.1 \\
\hline BpPOD47 & Bpev01.c0518.g0010.mRNA1 & VIT_207s0130g00220.1.v2.1 \\
\hline BpPOD48 & Bpev01.c0566.g0037.mRNA1 & VIT_214s0068g01920.1.v2.1 \\
\hline BpPOD49 & Bpev01.c0577.g0019.mRNA1 & VIT_218s0001g01140.1.v2.1 \\
\hline BpPOD51 & Bpev01.c0605.g0024.mRNA1 & VIT_211s0016g05280.1.v2.1 \\
\hline BpPOD52 & Bpev01.c0672.g0007.mRNA1 & VIT_204s0008g07040.1.v2.1 \\
\hline BpPOD57 & Bpev01.c0848.g0029.mRNA1 & VIT_201s0026g00830.1.v2.1 \\
\hline BpPOD58 & Bpev01.c0932.g0013.mRNA1 & VIT_205s0077g00720.1.v2.1 \\
\hline BpPOD65 & Bpev01.c1163.g0010.mRNA1 & VIT_210s0116g00340.1.v2.1 \\
\hline BpPOD68 & Bpev01.c1230.g0004.mRNA1 & VIT_219s0085g01040.1.v2.1 \\
\hline BpPOD70 & Bpev01.c1519.g0002.mRNA1 & VIT_201s0026g00830.1.V2.1 \\
\hline BpPOD70 & Bpev01.c1519.g0002.mRNA1 & VIT_217s0000g07750.1.v2.1 \\
\hline BpPOD71 & Bpev01.c1529.g0006.mRNA1 & VIT_210s0003g00650.1.v2.1 \\
\hline BpPOD72 & Bpev01.c1719.g0005.mRNA1 & VIT_218s0001g15390.1.v2.1 \\
\hline BpPOD74 & Bpev01.c1776.g0002.mRNA1 & VIT_214s0060g00510.1.v2.1 \\
\hline BpPOD78 & Bpev01.c1922.g0001.mRNA1 & VIT_212s0055g00980.1.v2.1 \\
\hline BpPOD80 & Bpev01.c2035.g0001.mRNA1 & VIT_205s0077g00880.1.v2.1 \\
\hline BpPOD84 & Bpev01.c2220.g0001.mRNA1 & VIT_216s0100g00740.1.v2.1 \\
\hline BpPOD84 & Bpev01.c2220.g0001.mRNA1 & VIT_216s0022g02470.1.v2.1 \\
\hline BpPOD84 & Bpev01.c2220.g0001.mRNA1 & VIT_216s0100g00090.1.v2.1 \\
\hline BpPOD88 & Bpev01.c3139.g0001.mRNA1 & VIT_212s0028g01840.1.v2.1 \\
\hline
\end{tabular}




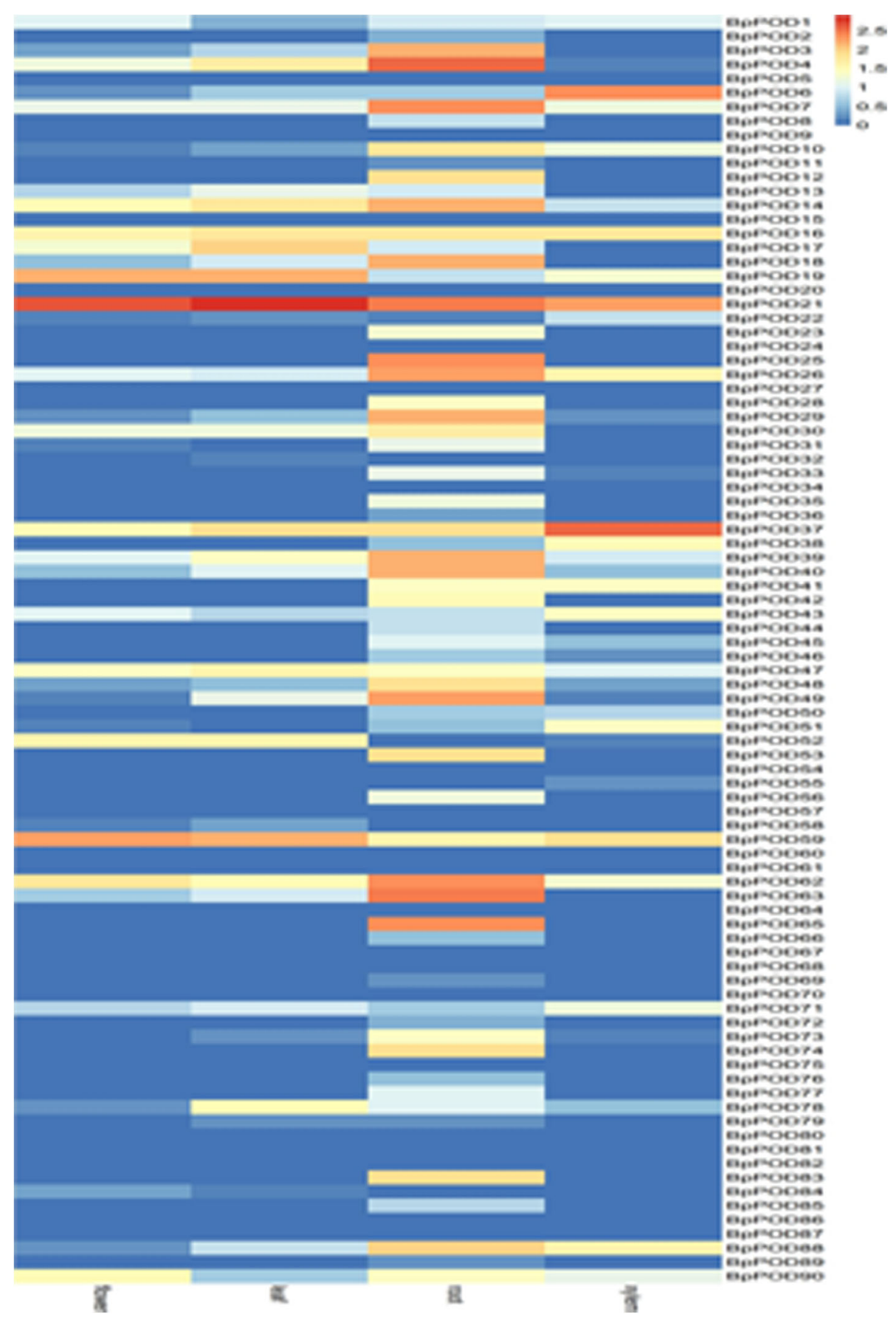

Fig. 7 Expression profiles of BpPOD genes across different tissues. Different tissues are exhibited below each column. The BpPOD genes were listed at the right of the expression array, and the colour box from blue (0) to orange (2.5) indicate an increased expression level is shown at the right of the figure. Color scale represent the normalized value of the expression. For the sake of unified comparison, the normalized value of the expression was $\log 10$ transformed

\section{Differential expression profile of $B P P O D$ gene family}

To determine the expression patterns of BPPODs in different tissues in Betula platyphylla $\times$ Betula pendula, we downloaded the sequencing data from the NCBI SRA database with an accession number of PRJNA535361 (https://www.ncbi.nlm.nih.gov/sra/?term=PRJNA535361)
[16]. To identify the expression of BpPODs during cold treatment in Betula platyphylla $\times$ Betula pendula, we designed the experiment including six time points. In this study, two-month-old Betula platyphylla $\times$ Betula pendula plants grown in the greenhouse of Northeast Forestry University were exposed to low temperatures 


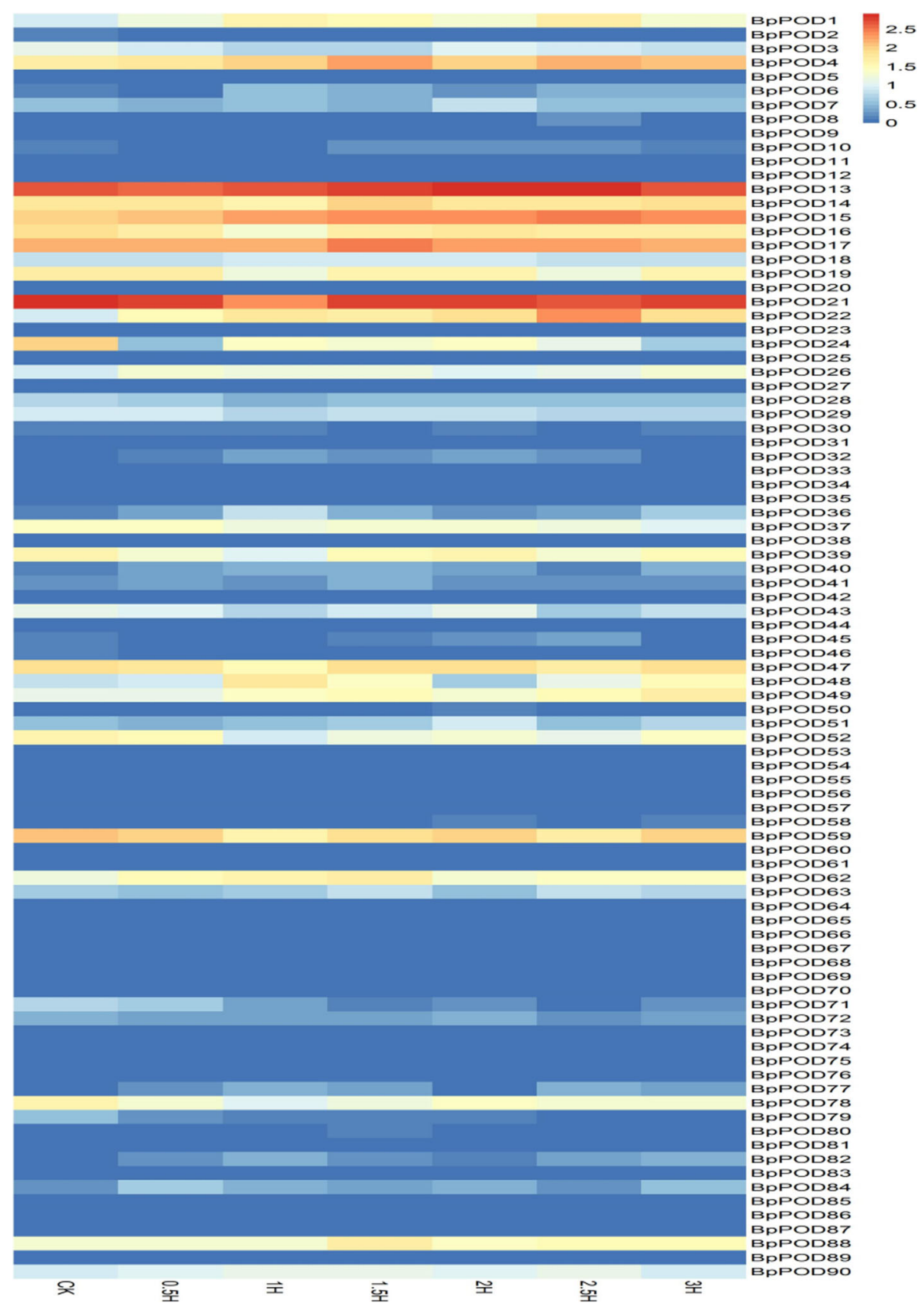

Fig. 8 Responses of BPPOD genes expression to cold treatment. Different time are exhibited below each column. The BPPOD genes were listed at the right of the expression array, and the colour box from blue (0) to orange (2.5) indicate an increased expression level is shown at the right of the figure. Color scale represent the normalized value of the expression. For the sake of unified comparison, the normalized value of the expression was $\log 10$ transformed

$\left(6^{\circ} \mathrm{C}\right)$ for $0.5 \mathrm{~h}, 1 \mathrm{~h}, 1.5 \mathrm{~h}, 2 \mathrm{~h}, 2.5 \mathrm{~h}$, and $3 \mathrm{~h}$, respectively [16]. In addition, plants without cold treatment were used as the control. After cold treatment, all young leaves were harvested at the same time to avoid changes in gene expression due to different harvest times. Total RNA samples were isolated from the leaves using the RNAprep Kit. The constructed cDNA libraries were sequenced using the Illumina HiSeq platform at Biomarker
Technologies Corporation (Beijing, China). We can downloaded the sequencing data from the NCBI SRA database with an accession number of PRJNA532995 (https://www. ncbi.nlm.nih.gov/sra/?term=PRJNA532995) [16].

\section{qRT-PCR test}

To evaluate the reliability of the RNA-seq data, six randomly BPPODs with cold treatment were selected and 


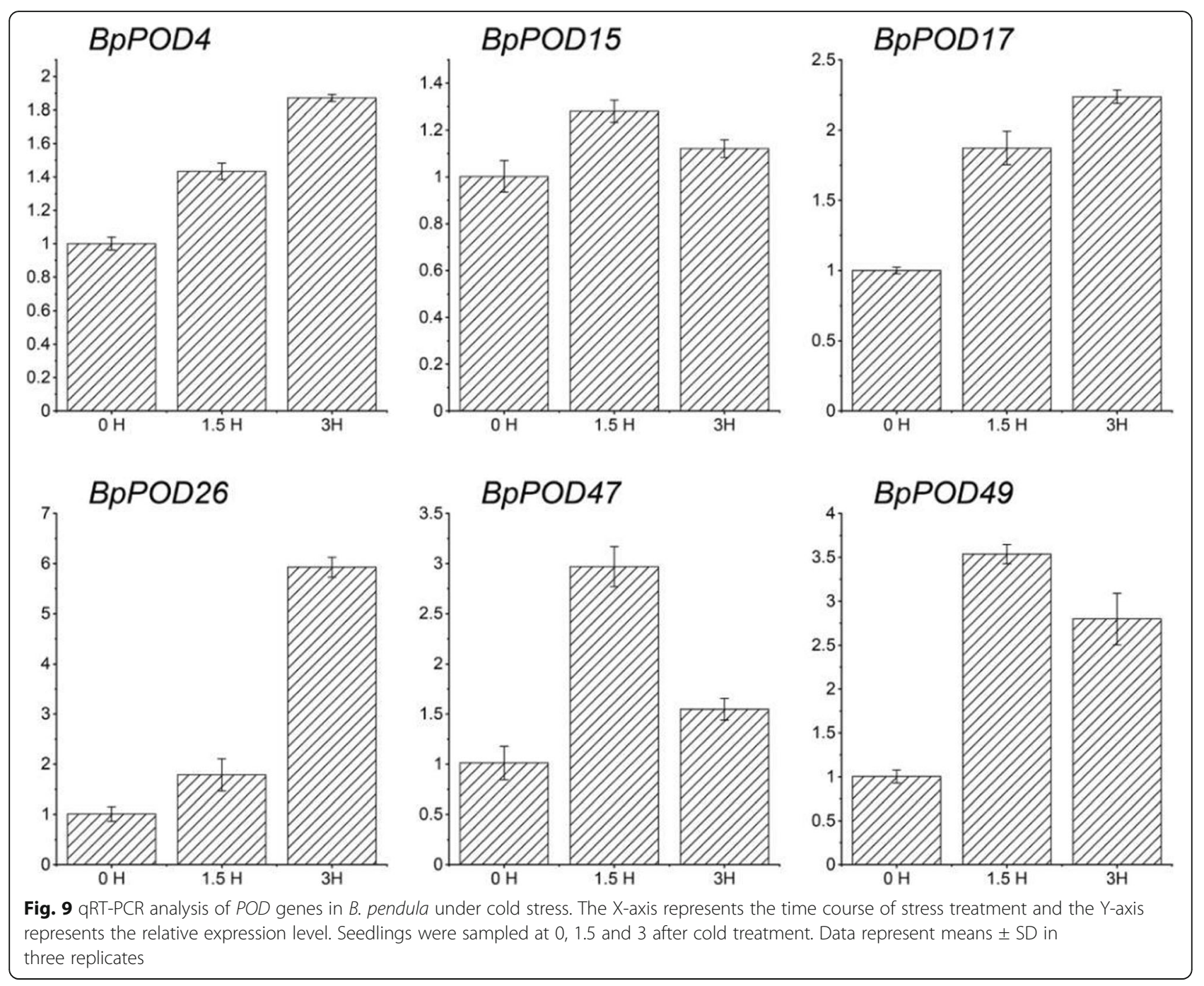

Table 6 BpPOD gene-specific primers used for qRT-PCR analysis

\begin{tabular}{lll}
\hline ID & BpPOD gene name & Primer sequences (5' to $\mathbf{3}^{\prime}$ ) \\
\hline 1 & BpPOD4-F & GTGGAGTTGGAAGACTAGATGG \\
2 & BpPOD4-R & GCAATCATATCGGTTGGGTGAG \\
3 & BpPOD15-F & TCTTGCCTCTCCCAATTCTACC \\
4 & BpPOD15-R & GAAAACTACACACCGTGCTTCTC \\
5 & BpPOD17-F & CTATCCTCCGCTTGTTITCCAC \\
6 & BpPOD17-R & TCTGACAGAGTTTCGATTGGGAG \\
7 & BpPOD26-F & GTGGCCTAATCACTTCCTTCTCA \\
8 & BpPOD26-R & TGTGGACTAGTGACGTCAAGAG \\
9 & BpPOD47-F & CAAACGTTGAGTCTACTGTGCAG \\
10 & BpPOD47-R & TACAGTGTCAAACCCATCTCCTG \\
11 & BpPOD49-F & TCGGATCAAGCTCTTCTCACAAA \\
12 & BpPOD49-R & AACTACTTGCAGTCGAGCCTAA \\
13 & 18S-F & GAGGTAGCTTCGGGCGCAACT \\
14 & 18S-R & GCAGGTTAGCGAAATGCGATAC \\
\hline
\end{tabular}

examined by qRT-PCR analysis. Total RNA of leaves of collected samples were extracted and purified using DNase I digestion (Takara, Dalian, China) to remove mixed DNA. Quantitative real-time RT-PCR was performed on an ABI 7500 Real-Time system (Applied Biosystems). The primers were designed using A plasmid Editor v1.11 (Table 6), and 18S rRNA was used as a reference gene. The PCR reaction protocol was conducted with $20 \mu \mathrm{l}$ volume containing $94^{\circ} \mathrm{C}$ for 30s, followed by 45 cycles of $94{ }^{\circ} \mathrm{C}$ for $5 \mathrm{~s}, 60^{\circ} \mathrm{C}$ for $35 \mathrm{~s}, 95^{\circ} \mathrm{C}$ for $15 \mathrm{~s}$, $60{ }^{\circ} \mathrm{C}$ for $1 \mathrm{~min}$, followed by $95^{\circ} \mathrm{C}$ for $15 \mathrm{~s}$. The relative expression level was determined according to the $2^{-\Delta \Delta C T}$ method. Three biological replicates were carried out for each sample.

\section{Abbreviations}

POD: Class III peroxidases; B. pendula: Betula pendula; BPPODs: POD genes in Betula pendula; RNA-seq: RNA sequencing

Acknowledgements

Not applicable. 


\section{Authors' contributions}

KWC was a major contributor in writing the manuscript. HXL drafted the manuscript and substantially revised it. SC1 analyzed the data and make figures. YL participated in RNA extraction and performed RT-qPCR assay. XYZ participated in the design of the study and analyzed data. SC2 conceived of the study, participated in its design and data interpretation, and revised the manuscript critically. The author(s) read and approved the final manuscript.

\section{Funding}

This research was supported by the National Natural Science Foundation of China (31870659), the Fundamental Research Funds for the Central Universities (2572019CG08) and Heilongjiang Touyan Innovation Team Program (Tree Genetics and Breeding Innovation Team).

\section{Availability of data and materials}

All data generated or analysed during this study are included in this published article.

\section{Declarations}

\section{Ethics approval and consent to participate}

Not applicable.

\section{Consent for publication}

Not applicable.

\section{Competing interests}

The authors declare that they have no competing interests.

\section{Received: 13 May 2020 Accepted: 15 April 2021}

Published online: 01 May 2021

\section{References}

1. Dunford HB, Stillman JS. On the function and mechanism of action of peroxidases. Coord Chem Rev. 1976;19(3):187-251. https://doi.org/10.1016/ S0010-8545(00)80316-1.

2. Passardi F, Theiler G, Zamocky M, Cosio C, Rouhier N, Teixera F, et al. PeroxiBase: the peroxidase database. Phytochemistry. 2007;68(12):1605-11. https://doi.org/10.1016/.phytochem.2007.04.005.

3. Mei W, Qin Y, Song W, Li J, Zhu Y. Cotton GhPOX1 encoding plant class III peroxidase may be responsible for the high level of reactive oxygen species production that is related to cotton fiber elongation. J Genet Genomics. 2009;36(3):141-50. https://doi.org/10.1016/S1673-8527(08)60101-0.

4. Martínez-Rubio R, Acebes JL, Encina A, Krknen A. Class III peroxidases in cellulose deficient cultured maize cells during cell wall remodeling. Physiol Plant. 2018;164(1):45-55.

5. Zhang Z, Xin W, Wang S, Zhang X, Wang Q. Xylem sap in cotton contains proteins that contribute to environmental stress response and cell wall development. Funct Integr Genomics. 2014;15(1):17-26. https://doi.org/10.1 007/s10142-014-0395-y.

6. Tognolli M, Penel C, Greppin H, Simon P. Analysis and expression of the class III peroxidase large gene family in Arabidopsis thaliana. Gene. 2002; 288(1-2):0-138. https://doi.org/10.1016/S0378-1119(02)00465-1.

7. Moural TW, Lewis KM, Barnaba C, Zhu F, Kang CH. Characterization of class III peroxidases from switchgrass. Plant Physiol. 2016;173(1):417-33.

8. Delannoy E, Jalloul LA, Assigbetsé K, Marmey P, Nicole M. Activity of class III peroxidases in the defense of cotton to bacterial blight. Mol Plant Microbe Interact. 2003;16(11):1030-8. https://doi.org/10.1094/MPMI.2003.16.11.1030.

9. Rácz A, Hideg É, Czégény G. Selective responses of class III plant peroxidase isoforms to environmentally relevant UV-B doses. J Plant Physiol. 2018;221: 101-6. https://doi.org/10.1016/j.jplph.2017.12.010.

10. Wang Y, et al. Comparative genomic analysis of the WRKY III gene family in populus, grape, arabidopsis and rice. Biol Direct. 2015;10(1):1-27.

11. Passardi F, Longet $D$, Penel $C$, Dunand C. The class III peroxidase multigenic family in rice and its evolution in land plants. Phytochemistry. 2004;65(13): 1879-93. https://doi.org/10.1016/j.phytochem.2004.06.023.

12. Passardi F, Cosio C, Penel C, Dunand C. Peroxidases have more functions than a Swiss army knife. Plant Cell Rep. 2005;24(5):255-65. https://doi.org/1 0.1007/s00299-005-0972-6.
13. Hiraga S, Sasaki K, Ito H, Ohashi Y, Matsui H. A large family of class III plant peroxidases. Plant Cell Physiol. 2001;42(5):462-8. https://doi.org/10.1093/ $\mathrm{pcp} /$ pce061.

14. Ritonga FN, Chen S. Physiological and molecular mechanism involved in cold stress tolerance in plants. Plants. 2020;9(5):560.

15. Hu Y, Peuke AD, Zhao X, Yan J, Li C. Effects of simulated atmospheric nitrogen deposition on foliar chemistry and physiology of hybrid poplar seedlings. Plant Physiol Biochem. 2019;143:94-108. https://doi.org/10.1016/j. plaphy.2019.08.023.

16. Chen S, Lin X, Zhang D, Li Q, Chen S. Genome-wide analysis of NAC gene family in Betula pendula. Forests. 2019;10(9):741. https://doi.org/10.3390/f1 0090741.

17. Alonso-Serra J, Safronov O, Lim K-J, Fraser-Miller SJ, Blokhina OB, Campilho $A$, et al. Tissue-specific study across the stem reveals the chemistry and transcriptome dynamics of birch bark. New Phytol. 2019;222(4):1816-31. https://doi.org/10.1111/nph.15725.

18. Sturtevant EL, Sturtevant EL. Sturtevant's edible plants of the world; 1972.

19. Johnson CP, Sowrby JE. Useful plants of Great Britain; 1899.

20. Huystee RBV. Some molecular aspects of plant peroxidase biosynthetic studies. Annu Rev Plant Biol. 2003;38(1):205-19.

21. Mittler R, Zilinskas BA. Molecular-cloning and characterization of a gene encoding pea cytosolic ascorbate peroxidase. J Biol Chem. 1992;267(30): 21802-7. https://doi.org/10.1016/50021-9258(19)36683-9.

22. Christensen JH, Bauw G, Welinder KG, Montagu MV, Boerjan W. Purification and characterization of peroxidases correlated with lignification in poplar xylem. Plant Physiol. 1998;118(1):125-35. https://doi.org/10.1104/pp.118.1.12 5.

23. Lewis NG. Lignin: occurrence, biogenesis and biodegradation. Annu Rev Plant Physiol Plant Mol Biol. 1990;41(1):455-96. https://doi.org/10.1146/a nnurev.pp.41.060190.002323.

24. Agostini E, Forchetti SMD, Tigier HA. Production of peroxidases by hairy roots of Brassica napus. Plant Cell Tissue Organ Cult. 1997;47(2):177-82. https://doi.org/10.1007/BF02318955.

25. Botella MA, Quesada MA, Kononowicz AK, Bressan RA, Valpuesta V. Characterization and in situ localization of a salt-induced tomato peroxidase mRNA. Plant Mol Biol. 1994;25(1):105-14. https://doi.org/10.1007/BF000242 02.

26. Chittoor JM, Leach JE, White FF. Differential induction of a peroxidase gene family during infection of rice by Xanthomonas oryzae pv. Oryzae. Mol Plant Microbe Interact. 1997;10(7):861-71. https://doi.org/10.1094/MPMI.1997.10.7. 861.

27. Zhang R, Yang C, Wang C, Wei Z, Xia D, Wang Y, et al. Time-course analyses of abscisic acid level and the expression of genes involved in abscisic acid biosynthesis in the leaves of Betula platyphylla. Mol Biol Rep. 2012;39(3): 2505-13. https://doi.org/10.1007/s11033-011-1002-0.

28. Ma Q, Sun T, Li S, Wen J, Zhu L, Yin T, et al. The Acer truncatum genome provides insights into nervonic acid biosynthesis. Plant J. 2020;104(3):66278. https://doi.org/10.1111/tpj.14954.

29. Salojrvi J, Smolander OP, Nieminen K, Rajaraman S, Kangasjrvi J. Genome sequencing and population genomic analyses provide insights into the adaptive landscape of silver birch. Nat Genet. 2017;49(6):904-12. https://doi. org/10.1038/ng.3862.

30. Chen S, Wang Y, Yu L, Zheng T, Wang S, Yue Z, et al. Genome sequence and evolution of Betula platyphylla. Hortic Res. 2021;8(1):1-12.

31. Cao Y, Han Y, Meng D, Li D, Jin Q, Lin Y, et al. Structural, evolutionary, and functional analysis of the class III peroxidase gene family in Chinese pear (Pyrus bretschneideri). Front Plant Sci. 2016;7:1874.

32. Punta M, Coggill PC, Eberhardt RY, Mistry J, Tate J, Boursnell C, et al. The Pfam protein families database. Nucleic Acids Res. 2004;28(1):263-6.

33. Letunic I, Doerks T, Bork P. SMART 7: recent updates to the protein domain annotation resource. Nucleic Acids Res. 2012;40(D1):D302-5. https://doi. org/10.1093/nar/gkr931.

34. Ren LL, Liu YJ, Liu HJ, Qian TT, Qi LW, Wang XR, et al. Subcellular relocalization and positive selection play key roles in the retention of duplicate genes of Populus class III peroxidase family. Plant Cell. 2014;26(6): 2404-19. https://doi.org/10.1105/tpc.114.124750

35. Duan $\mathrm{P}$, et al. Genome-wide identification and analysis of class iii peroxidases in allotetraploid cotton (Gossypium hirsutum L.) and their responses to pk deficiency. Genes. 2019;10(6):473.

36. Wang Y, Wang Q, Zhao Y, Han G, Zhu S. Systematic analysis of maize class III peroxidase gene family reveals a conserved subfamily involved in abiotic 
stress response. Gene. 2015;566(1):95-108. https://doi.org/10.1016/j.gene.201 5.04.041.

37. Moore RC, Purugganan MD. The early stages of duplicate gene evolution. Proc Natl Acad Sci. 2003;100(26):15682-7. https://doi.org/10.1073/pnas.253 5513100.

38. Cannon SB, Mitra A, Baumgarten A, Young ND, May G. The roles of segmental and tandem gene duplication in the evolution of large gene families in Arabidopsis thaliana. BMC Plant Biol. 2004;4:1-21.

39. Riechmann J, Heard J, Martin G, Reuber L, Jiang C, Keddie J, et al. Arabidopsis transcription factors: genome-wide comparative analysis among eukaryotes. Science. 2000;290(5499):2105-10. https://doi.org/10.1126/ science.290.5499.2105.

40. Elsheery NI. Genome-wide characterization of aspartic protease (AP) gene family in Populus trichocarpa and identification of the potential PtAPs involved in wood formation. BMC Plant Biol. 2019:19(276):1-17.

41. Ning K, et al. Transcriptome profiling revealed diverse gene expression patterns in poplar (Populusxeuramericana) under different planting densities. PLoS One. 2019;14(5):e0217066.

42. Cosio C, Dunand C. "Specific functions of individual class III peroxidase genes". J Exp Bot. 2009;60(2):391-408. https://doi.org/10.1093/jxb/ern318.

43. Llorente F, López-Cobollo RM, Catalá R, Martínez-Zapater JM, Salinas J. A novel cold-inducible gene from Arabidopsis, $\mathrm{RCl} 3$, encodes a peroxidase that constitutes a component for stress tolerance. Plant J. 2002;32(1):13-24. https://doi.org/10.1046/j.1365-313X.2002.01398.X.

44. Hu X, Liu C, Tian J, Zhang Y, Xin Q, Chen A, et al. Identification, molecular characterization, and expression analysis of the SQUAMOSA PROMOTER BINDING PROTEIN-LIKE (SPL) gene family in Betula platyphylla Suk. Trees. 2020;34(1):229-41. https://doi.org/10.1007/s00468-019-01913-7.

45. Mehanathan M, Rohit K, Bhan YC, Suresh BV, Yusuf K, Manoj P, et al. Identification and molecular characterization of MYB transcription factor superfamily in C4 model plant foxtail millet (Setaria italica L.). PLoS One. 2014;9(10):e109920.

46. Han Y, Ding T, Su B, Jiang H. Genome-wide identification, characterization and expression analysis of the chalcone synthase family in maize. Int J Mol Sci. 2016;17(2):161. https://doi.org/10.3390/ijms17020161.

47. Rogozin IB, Wolf YI, Sorokin AV, Mirkin BG, Koonin EV. Remarkable Interkingdom conservation of intron positions and massive, lineage-specific intron loss and gain in eukaryotic evolution. Curr Biol. 2003;13(17):1512-7. https://doi.org/10.1016/50960-9822(03)00558-X.

48. Oakley T, Ostman B, Wilson A. Repression and loss of gene expression outpaces activation and gain in recently duplicated fly genes. Proc Natl Acad Sci U S A. 2006;103(31):11637-41. https://doi.org/10.1073/pnas. 0600750103.

49. Albrecht V, Weinl S, Blazevic D, D'Angelo C, Batistic O, Kolukisaoglu Ü, et al. The calcium sensor CBL1 integrates plant responses to abiotic stresses. Plant J. 2003;36(4):457-70. https://doi.org/10.1046/j.1365-313X.2003.01892.x.

50. Kasuga M, Liu Q, Miura S, Yamaguchi-Shinozaki K, Shinozaki K. Improving plant drought, salt, and freezing tolerance by gene transfer of a single stress-inducible transcription factor. Nat Biotechnol. 1999;17(3):287-91. https://doi.org/10.1038/7036

51. Finn RD, Mistry J, Schuster-Bckler B, Griffiths-Jones S, Bateman A. PFAM: clans, web tools and services. Nucleic Acids Res. 2006;34(Database issue): D247-51. https://doi.org/10.1093/nar/gkj149.

52. Letunic I, Doerks TT, Bork P. SMART 6: recent updates and new developments. Nuclc Acids Res. 2008;37(Database issue):D229-32.

53. Thompson JD, Higgins DG, Gibson TJ. CLUSTAL W: improving the sensitivity of progressive multiple sequence alignment through sequence weighting, position-specific gap penalties and weight matrix choice. Nucleic Acids Res. 1994;22(22):4673-80. https://doi.org/10.1093/nar/22.22.4673.

54. Elisabeth G, Alexandre G, Christine H, Ivan I, Appel RD, Amos B. ExPASy: the proteomics server for in-depth protein knowledge and analysis. Nuclc Acids Res. 2003;31(13):3784-8.

55. Edgar RC. MUSCLE: multiple sequence alignment with high accuracy and high throughput. Nucleic Acids Res. 2004;32(5):1792-7. https://doi.org/10.1 093/nar/gkh340

56. Guo AY, Zhu QH, Chen X, Luo JC. GSDS: a gene structure display server. Hereditas. 2007;29(8):1023-6.

57. Bailey $\mathrm{TL}$, Elkan $\mathrm{C}$. The value of prior knowledge in discovering motifs with MEME. Ismb. 1995;3:21-9.
58. Chen C, Chen H, Zhang Y, et al. TBtools: an integrative toolkit developed for interactive analyses of big biological data. Mol plant. 2020;13(8):1194-202. https://doi.org/10.1016/j.molp.2020.06.009.

59. Wang Y, Tang H, Debarry JD, Tan X, Li J, Wang X, et al. MCScanX: a toolkit for detection and evolutionary analysis of gene synteny and collinearity. Nucleic Acids Res. 2012;40(7):e49.

\section{Publisher's Note}

Springer Nature remains neutral with regard to jurisdictional claims in published maps and institutional affiliations.
Ready to submit your research? Choose BMC and benefit from:

- fast, convenient online submission

- thorough peer review by experienced researchers in your field

- rapid publication on acceptance

- support for research data, including large and complex data types

- gold Open Access which fosters wider collaboration and increased citations

- maximum visibility for your research: over $100 \mathrm{M}$ website views per year

At BMC, research is always in progress.

Learn more biomedcentral.com/submissions 